\title{
Shear strengthening of RC beams by means of vertical prestressed reinforcement
}

\author{
Denise Ferreira*, Jesús Bairán, Antonio Marí \\ Department of Construction Engineering, Universitat Politècnica de Catalunya (UPC) - \\ Barcelona TECH, Campus Nord, C/ Jordi Girona 1-3, Mod C1. 08034, Barcelona, Spain
}

* First author and corresponding author:

Denise Ferreira

Universitat Politècnica de Catalunya (UPC) - Barcelona TECH

Department of Construction Engineering

Campus Nord, C/ Jordi Girona 1-3, Mod C1, 08034 Barcelona, Spain

E-mail address: denise.carina.santos@upc.edu

Tel: +34 934017435; Fax: +34 934054135

Second author:

Jesús Bairán

Universitat Politècnica de Catalunya (UPC) - Barcelona TECH

Department of Construction Engineering

Campus Nord, C/ Jordi Girona 1-3, Mod C1, 08034 Barcelona, Spain

E-mail address: jesus.miguel.bairan@ upc.edu

Third author:

Antonio Marí

Universitat Politècnica de Catalunya (UPC) - Barcelona TECH

Department of Construction Engineering

Campus Nord, C/ Jordi Girona 1-3, Mod C1, 08034 Barcelona, Spain

E-mail address: antonio.mari@ upc.edu 


\title{
Shear strengthening of RC beams by means of vertical prestressed reinforcement
}

\begin{abstract}
Strengthening RC elements critical to shear with prestressed transversal reinforcement can be an efficient method to increase the shear resistance of structures, allowing the development of the full flexural capacity. However, research on the performance of this technique is very scant, and methods for designing the optimum amount of prestressed transversal reinforcement and assessing the retrofitted structure have not been produced yet. Nonlinear FE models are an important tool regarding predicting the efficiency of these interventions. In this paper a shear-sensitive fibre beam formulation is extended in order to account for the effects of unbonded vertical external prestressed reinforcement in the structural response of $\mathrm{RC}$ beams. The model is validated with experimental tests available in literature, succeeding in capturing the gain of shear strength brought by different strengthening solutions. A parametric study is performed to find the optimal quantity of transversal reinforcement that ensures flexural failure mechanism in a beam with insufficient internal shear reinforcement. The relative simplicity of the numerical model makes it suitable for engineering practice.
\end{abstract}

Keywords: RC beams, Shear, Strengthening, Post-tensioned stirrups, Nonlinear FE analysis, Fibre beam model. 


\section{Introduction}

Strengthening of existing RC structures is a topic of great relevance, due to the advanced aging and increasing loading solicitation in many infrastructures in developed countries. There is a rising demand for consistent methods to perform structural assessment of aging infrastructures, evaluate the needs of intervention and designing strengthening or retrofit measures. In order to perform adequate interventions in these structures it is essential to predict the efficiency of the strengthening measures in the structural response. This can be accomplished by means of numerical models that are able to consider damage and subsequent strengthening interventions in the structural response by means of nonlinear phased analysis techniques (Ferreira, Bairán and Marí 2013).

Strengthening measures to increase bending capacity of structures, such as longitudinal external prestressing, longitudinal laminates of fibre reinforced polymers (FRP), enlargement of concrete cross sections and the application of extra longitudinal reinforcement, have been extensively studied and applied in the past; e.g. (Souza and Appleton 1997; Bakis et al. 2002; Marí, Oller and Bairán 2011). The same cannot be said about shear. In fact, the understanding of the effects of shear strengthening in RC structures with insufficient shear strength remains an open research topic.

Shear can be critical for some existing structures, designed with old shear provisions, presenting low quantities of transversal reinforcement or exposed to important shear loadings. The deficiency of shear strength may lead to a brittle collapse. The fact that shear resistance mechanism of non-strengthened elements is not totally clarified (Fib 2010), acts like a drawback in the analysis of the strengthened elements, as the complexity of the problem increases significantly. Aspects, such as, the resistance mechanism of the strengthened element, the distribution of resisted shear force between original and strengthening materials, 
the bonding mechanism and the overall efficiency of a strengthening solution have motivated many experimental research works involving different strengthening materials and techniques

Adding extra transversal steel and enlarging the web of beams are, perhaps, the most commonly used methods. The existing concrete on the top of the slab is removed, new extra stirrups are put around the cross section and new concrete is casted or sprayed to the element. This method is efficient in increasing the shear capacity, as long as the bond between new and old concrete is ensured (Souza and Appleton 1997). However, it is a very intrusive and timeconsuming intervention and may affect functionality as the size of the elements varies. For cases demanding for a slight augment of shear resistance, the application of steel reinforced shotcrete or epoxy bonded steel plates are some common alternatives. The drawback of these methods is the risk of bonding loss due to the fact that the strengthening material is not anchored to the compressive zone, unless mechanical anchorages are used. Recent experimental works on using fibre reinforced concrete in shear-strengthening of RC beams can be found in (Ruano, Isla, Pedraza, Sfer and Luccioni 2014)

The use of externally bounded FRP has shown to be an efficient technique of strengthening and retrofitting damaged RC elements (FIB 2006). The reasons for its popularity are: immunity to corrosion, low weight, very high tensile strength, the stiffness can be adapted to the design requirements, large deformation capacity and practically unlimited availability of dimensions and shapes. Besides the many advantages, some drawbacks also exist, such as, linear elastic failure without plastic deformations, high cost, possible incompatibilities of thermal expansion coefficients with concrete and loss of stiffness when exposed to high temperatures, brittle delamination failures modes, especially if the laminate is not anchored in the concrete compression zone. Relevant experimental works on shear FRP strengthening include (Hadi 2003, Mosallam and Banerjee 2007, Khalifa and Nanni 2002, Taljsten 2003, Bousselham, A. and Chaallal, O. (2006)., Carolin, A. and Taljsten, B. (2005). 
There are also experimental studies on using prestressed CFRP shear straps for strengthening $\mathrm{RC}$, as presented in (Kesse and Lees 2007).

The application of external transversal steel reinforcement is an efficient method to increase shear resistance of RC cross-sections. These bars can either be post-tensioned or not. The use of prestressed transversal reinforcement can provide an active confinement to the concrete section and allow the development of the complete flexural capacity of the beams. Experimental studies on shear sensitive beams demonstrated that the inducement of transverse compressive forces by means of prestressed transversal reinforcements increased the shear capacity, increased the ductility and was able to avoid brittle shear failures, e.g. of these works are (Collins and Roper 1990; Aboutaha and Burns 1994; Adhikay and Mutusuyoshi 2006) (Altin, Tankut, Anil and Demirel 2003; Shamsai, Sezen and Khaloo 2007). The experimental testes performed by Altin et al. (2003) were selected to validate the model because the beams presented higher dimensions and had shear internal reinforcement, hence more near to practical applications. Also there were several specimens with different characteristics of a/d, quantity of internal transversal reinforcement and clamps. Also, detailed information on the experimental tests and results were available in the paper, making it possible to do a good quality model and a proper comparison of results.

Concerning to the numerical modelling, RC shear-strengthened members have not been extensively studied, and the existing nonlinear FE models are mainly focused on simulations involving FRP strengthening techniques and 2D/3D nonlinear FE models; some examples are (Hoque, Rattanawangcharoen and Shah 2007; Kim and Vecchio 2008; Lee, Ha and Afzal 2008). These methods are usually very complex, time consuming and demanding, requiring fine FE meshes and large numbers of parameters (some of difficult definition), that can hardly be applied in practice. For these reasons, 2D and 3D NLFEA models are almost exclusively used in academia and research contexts. Simplified models able to accurately 
predict the response of shear-strengthened elements are needed in order to spread the use of these measures in practice.

A shear-sensitive fibre beam model was recently developed and validated by the authors (Ferreira et al. 2013; Ferreira, Bairán, Marí and Faria 2014b). The 1D fibre beam model accounts for axial force-bending-shear force interactions in a computationally efficient manner and allows for the nonlinear, time-dependent and strengthening analysis of shear critical concrete frame structures. The Timoshenko beam theory is linked with a shearsensitive sectional model. Cracking is simulated through the smeared and rotating crack approach. The effects of shear and its interaction with normal forces are accounted in all levels of damage, from service to ultimate limit states. The performance of the nonlinear 1D model was compared against the results of 2D and 3D NLFE models in different contexts related with structural behaviour: simulation of a full scale loading test in a bridge presenting shear-related failure (Ferreira, Bairán and Marí 2014a), and the simulation of beam of large dimensions tested in bending after free shrinkage in the ambit of the International Benchmark 'ConCrack' (Ferreira, Crespo, Marí and Bairán 2014c).In spite of the conceptual relative simplicity of the formulation, the most important phenomena that describe the structural behaviour were accurately accounted. The few and reliable variables involved in the 1D model that lead to robust and accurate simulations and the fast computer calculations, represent important advantages in relation to $2 \mathrm{D}$ and 3D FE strategies. A further advantage is the easiness of interpretation of results, which is especially convenient for practical usage.

The shear-sensitive 1D fibre beam model was presented elsewhere (Ferreira 2013, Ferreira et al 2014b). A preliminary study on shear strengthening with bonded vertical prestressing was presented in (Ferreira et al. 2013) but without comparison with experimental results. This paper presents an enhancement of this model and a pioneer numerical feature in the context of shear-sensitive fibre beam models: the development of a consolidated formulation and implementation for shear strengthening of $\mathrm{RC}$ beams by means of external post-tensioned stirrups, bonded and unbounded, and its validation by comparing the results 
with experimental data available in literature. The model enables to design optimal shear strengthening solutions, as demonstrated in a parametric study.

\section{Numerical model}

The detailed description and validation of the shear-sensitive fibre beam model for concrete structures can be found elsewhere (Ferreira 2013; Ferreira et al. 2014b). Only a brief reference to the fundamentals of the model is presented in this paper focusing on the new formulation for vertical prestressing (unbonded and bonded).

\subsection{Fundamentals of the shear-sensitive fibre beam model}

The 1D model is a displacement-based fibre beam FE formulation for the nonlinear, time-dependent and phased analysis of reinforced and prestressed concrete frame structures. By these means, along with the possibility of simulating shear critical problems, the model is able to reproduce evolutionary construction phases, such as repair or strengthening interventions. The fundamentals of the shear-sensitive fibre beam model are represented in Figure 1 concerning different levels of analysis: structure, element, section and fibre. The model idealizes three dimensional RC frames with 1D beam elements of arbitrary cross section interconnected by nodes (Figure 1a). The cross section is discretized into fibres or layers of concrete and filaments of longitudinal steel (Figure 1b). Transversal reinforcement is accounted as smeared in the concrete fibres. For each FE, the longitudinal reinforcement is considered parallel to the longitudinal axis. The FE model is based on the Timoshenko beam theory and at the sectional level, a shear-sensitive model accounts for the axial force-bendingshear interaction in all levels of material damage (Figure 1c). The Bernoulli-Navier planesection theory is coupled with a constant shear stress constraint along the cross section leading to a 2D strain-stress state in the fibres (Figure 1d). 
The implemented constitutive laws are represented in Figure 2. A smeared and rotating crack approach is considered for concrete (Figure 2a). The Hognestad parabola is assumed for concrete in compression as the backbone curve. Different factors are considered for the determination of the various parameters of this curve $\left(f_{c}, \varepsilon_{0}, \varepsilon_{u}\right)$ to account for multiaxial strain-stress states. Softening (Vecchio and Collins 1986) and strength enhancement (Kupfer, Hilsdorf and Rusch 1969) factors are included for the respective states of compression-tension and biaxial compression. For the strengthened beams these properties are modified according to Mander's model (Mander, Priestley and Park 1988) in order to account for the confinement effects brought by the vertical prestressing. For concrete in tension a linear response is assumed before cracking and a tension stiffening curve is considered in the cracked stage. A modified version of the exponential tension stiffening curve of (Cervenka 1985) is used, being calibrated so that it produces null stiffening for beyond yielding of steel (Ferreira 2013; Ferreira et al. 2014b). The tensile strain when tensile stress is equal to zero is assumed as the yielding strain of steel as proposed by Mohr, Bairán and Mari 2010. Steel is only submitted to axial strains and stresses by means of uniaxial constitutive laws (Figure $2 \mathrm{~b}$ ): where $\mathrm{f}_{\text {sy }}$ and $\varepsilon_{\text {sy }}$ are the yielding stress and strain and $\mathrm{f}_{\text {su }}$ and $\varepsilon_{\text {su }}$ are the ultimate stress and strain, respectively. This constitutive law is used for the simulation of ordinary reinforcing steel and for prestressing steel.

\subsection{Formulation to account for shear effects}

As represented in Figure 1c, along with the plane section theory that computes the axial strain $\varepsilon x$ as

$$
\varepsilon_{x}(z)=\varepsilon_{0}+\phi_{y} . z
$$

(where $\varepsilon_{0}$ is the axial strain at the section reference axis and $\phi_{y}$ is the curvature with respect to the $y$-axis), the model assumes a shear force $V$ along the section defined in the first iteration as 


$$
V=\left\{\begin{array}{ll}
G^{*} A^{*} \gamma_{0} & \text { shear resistant fibres } \\
0 & \text { non shear resistant fibres }
\end{array}\right\}
$$

where $G^{*}$ is the transversal modulus (determined from the condensed stiffness matrix of the fibre, as explained in the following), $\gamma_{0}$ is the distortion at centroid axis and $A^{*}$ is the summation of the areas of the shear resistant fibres. In this manner the plane section theory is coupled with a shear stress constraint, and the determination of the fibre state is performed using a hybrid stress-strain input information. The strain-stress state of each fibre is determined by means of a inner iterative procedure as explained in (Ferreira et al. 2014b). The criteria for dividing the cross section into shear resistant and non shear resistant fibres are explained in (Ferreira et al. 2013); essentially the fibres that belong to the web of the cross section discounting the cover area are set as shear resistant; also the fibres located in a shear effective width of the flanges are considered as shear resistant. For each fibre, given the axial strain in concrete $\varepsilon_{x}$ and the assumed shear stress $\tau^{*}=\mathrm{V} / \mathrm{A}$, and using the equilibrium, compatibility and constitutive equations, the strain and stress states and the stiffness matrix of the fibre are determined, as described in the following.

In relation to the material modelling of concrete, a smeared cracked approach is assumed, and cracked concrete is treated as a material with orthotropic average stress-strain curves. The constitutive model is formulated in terms of average principal strains $\underline{\varepsilon} 12=\left[\varepsilon_{1} \varepsilon_{2}\right]^{\mathrm{T}}$ and average principal stresses $\underline{\sigma}_{12}=\left[\sigma_{1} \sigma_{2}\right]^{\mathrm{T}}$ (Figure 2a), in which the principal directions of the strain and stress tensors are assumed to be coincident (average in this context means that an average behaviour between the uncracked and cracked areas of concrete is considered).

In the principal referential axes, the 2D stress-strain state can be written as follows

$$
\begin{gathered}
\left\{\begin{array}{l}
\sigma_{1} \\
\sigma_{2} \\
\tau_{12}
\end{array}\right\}=D_{12}\left\{\begin{array}{l}
\varepsilon_{1} \\
\varepsilon_{2} \\
\gamma_{12}
\end{array}\right\} ; D_{12}=\left(\begin{array}{ccc}
E_{1} & 0 & 0 \\
0 & E_{2} & 0 \\
0 & 0 & G_{12}
\end{array}\right) \\
G_{12}=\frac{1}{2} \frac{\sigma_{1}-\sigma_{2}}{\varepsilon_{1}-\varepsilon_{2}}
\end{gathered}
$$


where $E_{1}$ and $E_{2}$ are the stiffness modulus in each principal direction and $G_{12}$ is the corotational transversal modulus determined by the expression of (Bazant 1983) which imposes that the angles of the principal directions of the stresses and strains are the same. Details about the concrete material formulation can be found in (Ferreira et al. 2014b).

Considering the 2D stress-strain state of the concrete part of the shear resistant fibre, upon rotation of the principal stiffness matrix $D_{12}$ (Eq. 3 ) to the local $x-z$ referential, a $3 \times 3$ stiffness matrix $D_{c}$ is obtained:

$$
\left(\begin{array}{l}
\Delta \sigma_{x} \\
\Delta \sigma_{z} \\
\Delta \tau_{x z}
\end{array}\right)^{c}=D_{c}\left(\begin{array}{l}
\Delta \varepsilon_{x} \\
\Delta \varepsilon_{z} \\
\Delta \gamma_{x z}
\end{array}\right) \quad D_{c}=\left(\begin{array}{ccc}
D_{11} & D_{12} & D_{13} \\
D_{21} & D_{22} & D_{23} \\
D_{31} & D_{32} & D_{33}
\end{array}\right)
$$

These referential transformations can be performed by the use of the following rotation matrices $T_{\varepsilon}$ and $T_{\sigma}$ :

$$
\begin{gathered}
\underline{\varepsilon}_{x z}=T_{\sigma}^{T} \underline{\varepsilon}_{12} \quad ; \quad \underline{\varepsilon}_{12}=T_{\varepsilon} \underline{\varepsilon}_{x z} \\
\underline{\sigma}_{x z}=T_{\varepsilon}^{T} \underline{\sigma}_{12} ; \quad \underline{\sigma}_{12}=T_{\sigma} \underline{\sigma}_{x z} \\
D_{c}=T_{\varepsilon}^{T} D_{12} T_{\varepsilon} \\
T_{\varepsilon}=\left(\begin{array}{ccc}
l_{1}^{2} & m_{1}^{2} & l_{1} m_{1} \\
l_{2}^{2} & m_{2}^{2} & l_{2} m_{2} \\
2 l_{1} l_{2} & 2 m_{1} m_{2} & l_{1} m_{2}+l_{2} m_{1}
\end{array}\right) ; T_{\varepsilon}^{-1}=T_{\sigma}^{T} ;\left[\begin{array}{l}
l_{1}=\cos \theta \\
m_{1}=\sin \theta
\end{array}\right]\left[\begin{array}{l}
l_{2}=-\sin \theta \\
m_{2}=\cos \theta
\end{array}\right]
\end{gathered}
$$

where $\theta$ is the angle between the principal tensile strain and the $x$-axis.

A fibre can have different $n_{k}$ configurations of transversal steel (different dispositions of stirrups), which considered in the model through its volumetric ratio $\rho_{s t, k}$ and are submitted to axial stresses $\sigma_{z}^{\text {st }}$ (along direction $z$ ). The increment of axial stresses in the transversal reinforcement $\Delta \sigma_{z}^{s t}$ (along the $z$-direction) is computed as

$$
\left(\begin{array}{l}
0 \\
\Delta \sigma_{z} \\
0
\end{array}\right)^{s t}=D_{s t}\left(\begin{array}{l}
0 \\
\Delta \varepsilon_{z} \\
0
\end{array}\right) ; \quad D_{s t}=\left(\begin{array}{ccc}
0 & 0 & 0 \\
0 & \rho_{s t} E_{s t} & 0 \\
0 & 0 & 0
\end{array}\right) ; \quad \rho_{s t} E_{s t}=\sum_{k=1}^{n_{k}}\left(\frac{A_{s t, k}}{s_{k} b_{k}} E_{s t, k}\right)
$$

The transversal steel is taken into account by summing the contributions of the different stirrups configurations ( $A_{s t, k}$ is the area of transversal steel, $b_{k}$ is the width of the cross-section 
and $s_{k}$ is the longitudinal spacing of each configuration of stirrups $k$ ). Compatibility requirements impose that the vertical strain in concrete and the strain in the transversal reinforcement are equal, being denoted as $\varepsilon_{z}$. No bond slip is considered. The stiffness matrix of the fibre $K_{\text {fibre }}$ is given by the summation of contributions of concrete and transversal reinforcement. The determination of the state of the fibre (stiffness matrix $K_{f i b r e}$ and internal resistant force $\left.S_{\text {fibre }}\right)$ is presented in the following section, including the effects of prestressing. The contribution of the fibres to the sectional stiffness matrix $K_{s e c}$ and internal force vector $\underline{S}_{s e c}$ are determined by the integration of stiffness and forces of all the fibres of the cross section, as:

$$
\begin{aligned}
& K_{\mathrm{sec}}^{c+s t}=\int T^{T} K_{\text {fibre }} T d A \\
& \underline{S}_{\mathrm{sec}}^{c+s t}=\int T^{T} \underline{S}_{\text {fibre }} d A
\end{aligned}
$$

where $A$ is the area of each fibre and $T$ is the Timoshenko transformation matrix that relates the generalized strains of the element to the strains in each fibre.

Longitudinal steel is considered under axial strain-stress state. The contribution of the longitudinal reinforcement for the cross-section can be computed as the integral of stiffness and stresses throughout all the filaments as

$$
\begin{aligned}
& K_{\mathrm{sec}}^{s l}=\int T_{s l}{ }^{T} E^{s l} T_{s l} d A_{s l} \\
& \underline{S}_{\mathrm{sec}}^{s l}=\int T_{s l}{ }^{T} \sigma_{x}^{s l} d A_{s l}
\end{aligned}
$$

where $A_{s l}$ is the area of each steel filament and $T_{s l}$ is the transformation matrix related to the plane section theory. 
The element used is a 2-nodeTimoshenko FE with linear shape functions. The determination of the element stiffness matrix $K_{\text {elem }}$ and the internal resistant load vector $F_{\text {elem }}$ use the sectional formulations formerly described:

$$
\begin{aligned}
& K_{\text {elem }}=\int B K_{\mathrm{sec}} B d x \\
& \underline{F}_{\text {elem }}=\int B^{T} \underline{S}_{\mathrm{sec}} d x
\end{aligned}
$$

These integrals are solved through the Gaussian Quadrature Method and reduced integration is considered in order to avoid shear locking. The nonlinear finite element model is implemented into a Newton Raphson framework in order to solve the global equations of equilibrium.

\subsubsection{Inclusion of transversal prestressed reinforcement}

At the fibre level, along direction $z$ the incremental tensile stresses in the transversal steel $\Delta \sigma_{z}^{s t}$ must equilibrate the incremental compression stresses in concrete $\Delta \sigma_{z}{ }^{c}$. When vertical prestress is applied at a given time-step, the prestressed transversal reinforcement is activated with a given stress as schematically represented in Figure 3. The equilibrium of stresses in concrete and transversal steel in the vertical direction at the fibre level are written as

$$
\Delta \sigma_{z}^{c}+\rho_{s t} \Delta \sigma_{z}^{s t}+\rho_{s p} \Delta \sigma_{z}^{s p}=0
$$

where $\rho_{s p}$ is the volumetric ratio and $\Delta \sigma_{z}^{s p}$ is the increment of axial stresses (along direction $\mathrm{z}$ ) of the transversal prestressing. For passive stirrups, the longitudinal stresses $\sigma_{z}{ }^{s t}$ are computed by:

$$
\Delta \sigma_{z}^{s t}=E_{s} \Delta \varepsilon_{z}
$$


For vertical prestressed reinforcement, the prestressing force is accounted as an offset strain $\varepsilon_{z}^{p}$ and the increment of axial stresses $\Delta \sigma_{z}^{s p}$ is given by:

$$
\Delta \sigma_{z}^{s p}=E_{s p}\left(\Delta \varepsilon_{z}^{p}+\varepsilon_{z}^{p, 0}\right)
$$

where $E_{s p}$ is the elasticity modulus of the prestressing steel. The determination of the increment of strain in the active stirrups $\Delta \varepsilon_{z}^{p}$ depends of the bond conditions of the tendons:

i) for bonded prestressed vertical reinforcement (Figure 3a) $\Delta \varepsilon_{z}^{p}$ is equal to the vertical strain in concrete $\varepsilon_{z}$ :

$$
\Delta \varepsilon_{z}^{p}=\Delta \varepsilon_{z}
$$

ii) for unbonded prestressed vertical reinforcement $\Delta \varepsilon_{z}^{p}$ depends on the cross section distortion or elongation between the two anchorage points ( $u_{p, t o p}$ and $\left.u_{p, b o t}\right)$. By neglecting friction losses (acceptable because tendons are usually short straight), $\Delta \varepsilon_{z}^{p}$ is determined by:

$$
\begin{aligned}
& \Delta \varepsilon_{z}^{p}=\frac{u_{p}}{L_{p}}=\frac{u_{p, t o p}-u_{p, b o t}}{L_{p}} \\
& u_{p}=u_{p, t o p}-u_{p, b o t}=\int_{L_{p}} \varepsilon_{z} d z \square \sum_{L_{p}} \Delta \varepsilon_{z i} h_{i}=\Delta \bar{\varepsilon}_{z} L_{p}
\end{aligned}
$$

were $\Delta \bar{\varepsilon}_{z}$ is equal to the mean vertical strain of the prestressing reinforcement given by the integral of vertical strains along the fibres of the web $\Delta \varepsilon_{z i}$ divided by the anchorage length of the tendons $\mathrm{L}_{\mathrm{p}}$ (Figure $3 \mathrm{~b}$ ), where $h_{i}$ is the width of each fibre $i$.

The stress state of a fibre with prestressing is schematically represented in Figure 4. Through the equilibrium requirement of Eq. (15) the concrete fibre is submitted to an active confinement when the vertical prestress is applied, and passive stirrups will be precompressed. From Eq. (5) the concrete stress along direction $z$ is computed as

$$
\Delta \sigma_{z}^{c}=D_{21} \Delta \varepsilon_{x}+D_{22} \Delta \varepsilon_{z}+D_{23} \Delta \gamma_{x z}
$$

Replacing Eq. (21) into Eq. (16) and making use of Eq. (10), the equilibrium in the vertical direction becomes: 


$$
D_{21} \Delta \varepsilon_{x}+D_{22} \Delta \varepsilon_{z}+D_{23} \Delta \gamma_{x z}+\rho_{s t} E_{s} \Delta \varepsilon_{z}+\rho_{s p} E_{s p}\left(\Delta \varepsilon_{z}^{p}+\Delta \varepsilon_{z}^{p, 0}\right)=0
$$

In addition to this equilibrium requirement, another condition needs to be fulfilled in order to determine the fibre state: the computed increment of shear stress $\Delta \tau_{x z}$ must equate the imposed increment of shear stress given by the fixed stress constraint $\Delta \tau^{*}$ :

$$
\Delta \tau^{*}-\Delta \tau_{x z}=0
$$

By solving the system of the two Eqs. (22) and (23), the 2D stress-strain of the fibre (composed by concrete and smeared transversal reinforcement) is obtained, and the complete stiffness matrix of the fibre $D_{\text {fibre }}$ is computed as the summation of both contributions (concrete and transversal reinforcement):

$$
\begin{gathered}
\left(\begin{array}{l}
\Delta \sigma_{x} \\
\Delta \sigma_{z} \\
\Delta \tau_{x z}
\end{array}\right)=D_{\text {fibre }}\left(\begin{array}{l}
\Delta \varepsilon_{x} \\
\Delta \varepsilon_{z} \\
\Delta \gamma_{x z}
\end{array}\right) ; D_{\text {fibre }}=\left(\begin{array}{ccc}
D_{11} & D_{12} & D_{13} \\
D_{21} & \bar{D}_{22} & D_{23} \\
D_{31} & D_{32} & D_{33}
\end{array}\right) ; \\
\bar{D}_{22}=D_{22}+\rho_{s t} E_{s} \Delta \varepsilon_{z}+\rho_{s p} E_{s p}\left(\Delta \varepsilon_{z}^{p}+\Delta \varepsilon_{z}^{p, 0}\right)
\end{gathered}
$$

The unknown increments of the vertical axial strain $\Delta \varepsilon_{z}$ and shear strain $\Delta \gamma_{x z}$ of each fibre can be determined as functions of the increments of $\Delta \varepsilon x$ and $\Delta \tau^{*}$ according to:

$$
\begin{gathered}
\Delta \varepsilon_{z}=f\left(\Delta \varepsilon_{x}, \Delta \tau^{*}, D_{\text {fibre }}\right)=\frac{\left(D_{23} D_{31}-D_{33} D_{21}\right) \Delta \varepsilon_{x}-D_{23} \Delta \tau^{*}}{\bar{D}_{22} D_{33}-D_{23} D_{32}} \\
\Delta \gamma_{x z}=f\left(\Delta \varepsilon_{x}, \Delta \tau^{*}, D_{\text {fibre }}\right)=\frac{\left(D_{23} D_{21}-\bar{D}_{22} D_{31}\right) \Delta \varepsilon_{x}+\bar{D}_{22} \Delta \tau^{*}}{\bar{D}_{22} D_{33}-D_{23} D_{32}}
\end{gathered}
$$

The flow of vertical and shear strains along the cross section determined by the model are schematically represented in Figure 3.

As stress $\sigma_{z}$ is null and the section model does not include $\varepsilon_{z}$, a static condensation is applied resulting in the condensed form of the stiffness matrix of the fibre $K_{f i b r e}$ 


$$
\left(\begin{array}{l}
\sigma_{x} \\
0 \\
\tau_{x z}
\end{array}\right)=\left(\begin{array}{lll}
D_{11} & D_{12} & D_{13} \\
D_{21} & \bar{D}_{22} & D_{23} \\
D_{31} & D_{32} & D_{33}
\end{array}\right)\left(\begin{array}{l}
\varepsilon_{x} \\
\varepsilon_{z} \\
\gamma_{x z}
\end{array}\right)
$$

and thus

$$
\left(\begin{array}{l}
\sigma_{x} \\
\tau_{x z}
\end{array}\right)=K_{\text {fibre }}\left\{\begin{array}{l}
\varepsilon_{x} \\
\gamma_{x z}
\end{array}\right\} ; K_{\text {fibre }}=\left(\begin{array}{cc}
D_{11}-\frac{D_{12} D_{21}}{\bar{D}_{22}} & D_{13}-\frac{D_{12} D_{23}}{\bar{D}_{22}} \\
D_{31}-\frac{D_{32} D_{21}}{\bar{D}_{22}} & D_{33}-\frac{D_{32} D_{23}}{\bar{D}_{22}}
\end{array}\right)
$$

where the shear modulus $\mathrm{G}^{*}$ in Eq. (2) is given by

$$
G^{*}=D_{33}-\frac{D_{32} D_{23}}{\bar{D}_{22}}
$$

More details about the mathematic derivations of these expressions can be found in the references (Ferreira 2013; Ferreira et al. 2013; Ferreira et al. 2014b).

\section{Validation}

\subsection{Experimental tests by Altin et. al. (2003)}

An experimental campaign was carried out by (Altin et al. 2003) with the objective of studying the effects of externally applied clamps on the behaviour and ultimate strength of beams with insufficient shear strength. It involved 13 beams divided into two series depending on the ratio between shear span and effective beam depth: $\mathrm{a} / \mathrm{d}=4.5$ (series S5) and $\mathrm{a} / \mathrm{d}=3.3$ (series S3). The beams present different levels of insufficient transversal reinforcement that is compensated with clamps (vertical prestressed reinforcement applied externally) in order to ensure a flexural response and to avoid shear failure. Different strengthening solutions were tested by varying the ratio and location of the clamps. Seven experimental tests with equidistant clamps were simulated with the numerical model, including the most representative results of the experimental campaign. The characteristics of the experimental tests under study are presented in Table 1 and in Figure 5. 
The beams present T-shape cross sections and were designed to be under-reinforced in shear. The span between supports is of 3,9 $\mathrm{m}$ for series $\mathrm{S} 5$ and of 3,0 $\mathrm{m}$ for series $\mathrm{S} 3$ as indicated in Table 1. The tensile longitudinal reinforcement $(3 \varnothing 20 \mathrm{~mm})$ is equal for all the specimens. Internal transversal reinforcement is produced by Ø6 in series S5 and Ø8 in series S3. Clamps consisted of two steel bars with $\varnothing 10 \mathrm{~mm}$ diameter and $0,5 \mathrm{~m}$ length and a steel box as represented in Figure 5 and detailed explained in (Altin et al. 2003). The clamps were connected to the beam and post-tensioned to 0.25 of the steel yielding strength $\left(f_{\text {sy }}=276.9\right.$ $\mathrm{MPa}$ ), representing an initial stress state of $69.2 \mathrm{MPa}$.

There are three control beams: S500 and S300 with sufficient internal stirrups to attain a flexural behaviour, representing a correct design for both series, respectively; S500-A is a shear critical beam without enough internal stirrups that requires shear strengthening to guarantee flexural behaviour.

The beams were monotonically loaded until failure under a symmetrical four point loading scheme. Loading was applied by a hydraulic jack and measured by a load cell. Midpoint deflections were measured by linear variable displacement transducers (LVDTs). In order to estimate average shear displacements in the webs of the beams, LVDTs were placed in the diagonals of rectangles with $0.3 \times 0.21 \mathrm{~m}$ for series $\mathrm{S} 5$ and $0.25 \times 0.21 \mathrm{~m}$ for series $\mathrm{S} 3$. The method for determination of shear displacements is explained in (Altin et al. 2003).

The experimental tests demonstrated that strengthening RC beams with insufficient shear capacity by means of external vertical prestressing succeeded in ensuring flexural behaviour. The application of the clamps controlled the propagation of cracks and improved the ductility of the members. 


\subsection{Numerical modelling}

The experimental tests were simulated with the presented numerical model. Figure 6 presents the longitudinal and sectional meshes, loads and support conditions considered in the simulation (dimensions relate to Table 1 for each series of tests); elements of $0.1-0.125 \mathrm{~m}$ of length and fibres of $5 \mathrm{~mm}$ of width were applied. The material properties used in the simulation are listed in Table 2 for concrete and Table 3 for steel, which were provided in (Altin et al. 2003). In relation to the concrete properties, the only experimental value provided

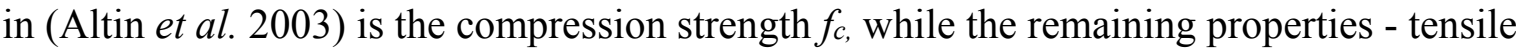
strength $f_{c t}$, ultimate strain $\varepsilon_{c u}$ and modulus of elasticity $E_{c}$ - were determined according to the expressions of Eurocode 2 EN1992-1 (CEN 2004). For the strengthened beams these properties were modified according to Mander's model (Mander, Priestley and Park 1988) in order to account for the confinement effects brought by the vertical prestressing. These values are also included in Table 3.

Load was applied incrementally until failure. In the strengthened beams, clamps were activated from the beginning of the analysis as unbonded prestressed stirrups with an initial strain of $\varepsilon_{\mathrm{p}}=0.00346$ (correspondent to $P_{c}=69.225 \mathrm{MPa}$ ) and an anchorage length of $\mathrm{L}_{\mathrm{p}}=0.4$ m.

\subsection{Results and discussion}

A general comparison between experimental and numerical results is presented in Table 4, in terms of loads, displacements and resistant mechanisms mobilized at: shear cracking stage, yielding and ultimate stages. Apart from beam S500A, all the other specimens presented a flexural failure mechanism, which is correctly predicted by the numerical model. Also, it can be observed from this table that the model provides accurate predictions for each level of damage.

In the numerical calculations, shear cracking load $V_{c s, n}$ is set as the load level for which the stirrups (located at the shear critical section) start to carry load. In relation to experimental results , $V_{c s, e}$ corresponds to the observation of the onset of diagonal cracks, according to (Altin et al. 2003). The diagonal cracking load $V_{c s, e}$ is well predicted by the numerical model 
(average ratio numerical / experimental values of 1.01). Yielding of longitudinal reinforcement is reached by all the specimens failing in bending. The shear force $V_{y, n}$ and displacement $d_{y, n}$ predicted by the model for the start of the yielding stage was also correctly predicted The model slightly underestimated the displacements at this stage but gave correct estimation of loads. (average ratio of numerical / experimental values of 0.99 for loads and 0.82 for displacements).

At failure stage, the ultimate loads $V_{u, e}$ were estimated by the model with good accuracy (average ratio numerical / experimental values of 0.99). The model presented a general underestimation of ultimate displacements $d_{u}$ (average ratio numerical / experimental values of 0.74$)$. This must be attributed to uncertainties of the ultimate strain of the reinforcement and limitations of the model to capture the full rotation of the plastic hinges formed during failure.

However, the increment of shear strength brought by the external vertical prestressing was correctly accounted by the model. In fact, the strengthened beams presented flexural failure mechanisms with ductile behaviour in contrast with the shear critical control beam with insufficient internal stirrups.

Experimental and numerical results are compared in the following in terms of total and shear displacements with increasing force for the different series of tests. Numerical shear displacements are determined by subtracting the flexural portion (determined by the pure flexural fibre beam model (Marí 2000)) to the total deflection determined by the proposed shear model. Experimentally, shear displacements are determined through the measurements from diagonal LVDTs as explained in (Altin et al. 2003).

Figure 7 presents the comparison of results for the control beams of series S5: the shear critical beam S500A and the flexural beam S500. A very good fitting between numerical and experimental results is perceived in these graphics. In the case of the beam S500A, a brittle shear failure was observed due to the insufficient shear reinforcement; and shear displacements were significant. The response of the flexural control beam S500 is well determined by the model, however, presenting less ductility than the experimental 
measurements. In this case, shear displacements are lesser than in beam S500A but also significant for the total response and well predicted by the model.

In Figure 8 the response of the strengthened beams of series S5 - S521 and S531 analysed by the model are compared with the response of the shear critical control beam S500A. It can be observed that the increment of shear resistance brought by the clamps is well captured by the model, allowing the development of the full flexural resistance of these beams. Again, the model gives good estimations of the overall response, failure load and shear displacements but underestimates the ultimate displacements, presenting less ductility.

An analogous presentation of results is made in Figure 9 for the specimens of series S3: flexural control beam S300 and strengthened beams S321 and S331. Overall response, ultimate load and shear displacements are very well predicted by the model.

\subsection{Load sharing between stirrups and clamps}

After the validation of the model, extra information that is not available from the experimental tests can be extracted and analyzed in order to better understand the structural behaviour. A key mechanism of these beams is the shear force distribution between the internal stirrups and the external vertical strengthening. This shared mechanism is responsible for bringing the sufficient shear resistance to the members that allows the development of the entire flexural capacity and ductile response.

The development of stresses in the stirrups and clamps with increasing load determined by the numerical model is represented in Figure 10 for all the analysed beams of series S5 (Figure 10a) and Series S3 (Figure 10b).

Pertaining to series S5, in the control flexural beam S500 it can be observed the abrupt loading of the stirrups, reaching yielding. Clamps present the initial prestressing stress and are only further solicited at higher load levels (after diagonal cracking) and reaching low levels of stresses. For the strengthened beams S521 and S531, stirrups are activated for higher load levels and develop less stresses in comparison with S500; this is related with the later diagonal cracking for higher load levels brought by the effects of vertical prestressing. Note 
that this also depends on $\mathrm{M} /(\mathrm{Vd})$ ratio: for series $\mathrm{S} 5(\mathrm{a} / \mathrm{d}=4.5)$ the increment of stresses in prestressing is noticed for $\mathrm{V}_{\mathrm{p}} / \mathrm{V}_{\mathrm{s}} \approx 2$ (Figure 10a), being $\mathrm{V}_{\mathrm{s}}$ the shear force correspondent to the activation of stirrups and $\mathrm{V}_{\mathrm{p}}$ to the activation of vertical prestressing reinforcement; while for series $\mathrm{S} 3(\mathrm{a} / \mathrm{d}=3.3)$ this value decreases to approximately 1.2 . This is due to the earlier distortion of the section for higher shear/bending ratio. In this last case, the activation of inner stirrups and clamps is closer, for shear force levels of approximately 50-60 kN (Figure 10b). In both cases an appreciable increment of elastic stresses is observed in the vertical prestressing reinforcement, around 100-200 MPa.

Analogous aspects can be observed for series S3. Here the difference in the stirrups response between control and strengthened beams is not as pronounced as in the series S5 and clamps are more solicited, as the effects of shear are more important in these specimens (presenting lower $\mathrm{M} /(\mathrm{Vd})$ ). Even tough, it can be observed that for the strengthened beams, activation of internal stirrups happens for higher loads in comparison with the control beam.

This information may be relevant for designing efficient and safe shear strengthening measures, regarding controlling diagonal cracking and stress levels in internal and external reinforcement.

\subsubsection{Influence of the bond condition of the clamps}

Analogous numerical simulations of the experimental tests were performed with the numerical model by considering the same external prestressed reinforcement but bonded instead of unbonded. This condition could be achieved by extra concreting of the web of the cross-section.

The development of stresses in stirrups and clamps with increasing load are represented in Figure 11 for two specimens of the series S3: S321 in Figure 11a and S331 in Figure $11 \mathrm{~b}$. These results refer to the element in the mid cross section, representative of a critical location for shear cracking and failure. If clamps are adherent to concrete they experience the same increment of strain as the internal stirrups. Consequently, after diagonal cracking and in the case of full adherence, clamps are more loaded and stirrups less loaded in 
comparison with the unbonded situation. This is perceptible for both cases. S331 presents higher quantity of clamps and lesser of stirrups, which leads to a lower decrements of stresses in clamps and higher increments in stirrups for the bonded situation in comparison with S321. Both bonded and unbonded elements fail at the same load because in the two cases failure mechanisms are controlled by bending.

In all the strengthened specimens failure was controlled by bending, therefore, it can be argued whether the shear reinforcement could be reduced.

\section{Minimum strengthening solution to ensure bending failure}

A parametric study was performed with the numerical model in order to find the optimal strengthening solution of the analyzed specimens. Hence, starting from the shear critical control beam of series S5 (specimen S500A without external prestressing and with insufficient inner transversal reinforcement) several analysis were carried out by successively increasing the quantity of clamps. These quantities varied from $0.0 \%$ (S500A) to $0.87 \%$ of the strengthened specimen 531. This study aims to determine the optimal quantity of strengthening clamps that ensures the gain of shear resistance between the shear critical specimen S500A and the strengthened flexural specimen S531 (Figure 12). In other words, the minimum shear resistance that ensures bending failure.

The different quantities of prestressed external reinforcement were considered by varying diameters $(\varnothing 6, \varnothing 8$ and $\varnothing 10)$ and separation of the clamps $(0.175 \mathrm{~m}$ to $0.5 \mathrm{~m})$ and maintaining the prestressing force and properties of steel. All the other characteristics of the model were the same as in the validation analyses, including considering unbonded clamps.

Figure 13 represents the ultimate shear load predicted by the model for the various quantities of strengthening clamps. The tested specimens - S500A and S531 - are marked as references. For quantities of clamps between $0 \%$ and $0.24 \%$, the predicted failure mechanism is brittle shear, being these quantities of transversal reinforcement insufficient to ensure flexural behaviour. In these cases, longitudinal reinforcement is kept linear until ultimate load and stirrups fail. Ultimate load increases with the augment of the quantity of strengthening 
vertical reinforcement as it brings gains of shear resistance to the element. From $0.24 \%$ to $0.28 \%$ of prestressing external vertical reinforcement, a shear-flexural failure mechanism is predicted, with yielding of both longitudinal reinforcement and failure of stirrups. From $0.28 \%$ forward, flexural resistance mechanism is always predicted with a rather constant ultimate load. Longitudinal reinforcement yields and a flexural failure mechanism is attained. From this quantity of strengthening forward, the increment of transversal reinforcement does not influence the ultimate load level and failure mechanism. From this analysis, a safe and efficient design of shear strengthening to ensure bending failure would be around $0.3 \%$ to $0.4 \%$, depending on the safety margin desired against shear failure . A quantity of $0.4 \%$ could be materialized in these beams by clamps of $\emptyset 8$ equidistantly spaced at $0.2 \mathrm{~m}$.

\section{Conclusion}

This paper presents a formulation to evaluate the effectiveness of shear strengthening by means of vertical prestressed reinforcement (clamps) in the response of RC beams. The formulation is developed and implemented in the ambit of a shear-sensitive fibre beam model previously developed by the authors. Different bonding conditions of the clamps, bonded and unbonded, are accounted by means of suitable assumptions. The model is validated with experimental tests available in literature and afterwards used to perform further numerical studies. From these numerical analyses, the following conclusions are drawn:

- The gain of shear strength with external vertical prestressed reinforcement is correctly captured by the model.

- Numerical results presented a general good fitting with experimental data in terms of total displacements and shear displacements with increasing load. Ultimate total displacements are often underestimated by the model, which may be due to uncertainties of the ultimate strain of the reinforcement and limitation of the model to capture full rotation of plastic hinges.

- This strengthening technique increased the shear capacity of members, allowing for the development of its full flexural capacity, which is correctly captured by the model. 
- The model determines the load sharing between stirrups and clamps; this distribution of stresses in the transversal reinforcement depends on the type of bonding conditions. These results may be relevant in designing strengthening solutions in order to ensure safe levels of stresses in the transversal reinforcement in both ultimate and service states.

- The elastic increment of stress in the unbonded clamps is relevant (around 100-200 $\mathrm{MPa})$.

- Vertical prestressing is activated earlier for lower ratios of $\mathrm{M} /(\mathrm{Vd})$.

- Regarding the studies on the bonding conditions of the clamps, it is observed that for the bonded case, clamps are more loaded and stirrups carry less load in comparison with the analogous unbonded situation.

- An optimal strengthening solution to ensure flexural failure was found by means of a parametric study in which different quantities of vertical prestressed reinforcement were considered for a shear critical beam. This study demonstrates the key advantage of the proposed model for practical applications.

- An optimum design of reinforcement, in series S5, was found between $0.3 \%$ and $0.4 \%$ of quantity of strengthening clamps. 
A possible line for future research is the development of an experimental campaign to validate the minimum quantity of vertical prestressing reinforcement ensuring bending failure and to provide more detailed data about the strains in the passive and active transversal reinforcement and the share of shear force. The numerical results showed that the resistant mechanism and failure mode changes in relation to the passive reinforcement, as the presence of vertical prestressing delays shear cracking and changes the inclination of the compression strain fields. Future research lines include developing an analytical method to design transversal prestressing reinforcement.Acknowledgements

The present research has been carried out with the support of the project "Performance-baseddesign of partially prestressed concrete structures. Proposal of new design methodology, experimental verification and design criteria.” (BIA2012-36848) co-financed by the Spanish Ministry of Economics and Competitiveness and the European Funds for Regional Development (FEDER). The Postdoctoral Fellowship conceded by the Government of Catalonia (ref. 2013 PDJ 00022) to the first author is also gratefully acknowledged.

\section{References}

Aboutaha, R. and Burns, N. (1994). Strengthening of prestressed concrete composite beams using external prestressed stirrups. PCI Journal, July-August: 65-74.

Adhikay, B. and Mutusuyoshi, H. (2006). Shear strengthening of reinforced concrete beams using various techniques. Construction and Building Materials, 20: 366-373.

Altin, S., Tankut, T., Anil, O. and Demirel, Y. (2003). Response of reinforced concrete beams with clamps applies externally: an experimental study. Engineering Structures, 25 : 1217-1229.

Bakis, C. E., Bank, L. C., Brown, V. L., Cosenza, E., Davalos, J. F., Lesko, J. J., Machida, A., Rizkalla, S. H. and Triantafillou, T. C. (2002). Fibre-reinforced polymer composites for construction - state-of-the-art review. Journal of Composites for Construction, 6(2): 7387.

Bousselham, A. and Chaallal, O. (2006). Behavior of RC T-beams strengthened in shear with CFRP: An experimental study. ACI Structural Journal, 103(3): 339-347.

Carolin, A. and Taljsten, B. (2005). Experimental study of strengthening for increased shear bearing capacity. Journal of Composites for Construction, 9(6): 488-496. 
CEN (2004). Eurocode 2. Design of Concrete Structures. Part 1-1: General rules and rules for buildings.

Cervenka, V. (1985). Constitutive model for cracked reinforced concrete. ACI Journal, 82(6): 877-882.

Collins, F. and Roper, H. (1990). Laboratory investigation of shear repair of reinforced concrete beams loaded in flexure. ACI Materials Journal, 97(2): 149-159.

Ferreira, D. (2013). A model for the nonlinear, time-dependent and strengthening analysis of shear critical frame concrete structures. Departament D'Enginyeria de la Construcció. Barcelona, Universitat Politècnica de Catalunya. Escola Tècnica Superior d'Enginyers de Camins, Canals i Ports. PhD Thesis.

Ferreira, D., Bairán, J. M. and Marí, A. (2013). Numerical simulation of shear-strengthened RC beams. Engineering Structures, 46: 359-374.

Ferreira, D., Bairán, J. M. and Marí, A. (2014a). Efficient 1D model for blind assessment of existing bridges: simulation of a full scale loading tests and comparison with higher order continuum models. Structure and Infrastructure Engineering, DOI:10.1080/15732479.2014.964734, Article in Press.

Ferreira, D., Bairán, J. M., Marí, A. and Faria, R. (2014b). Nonlinear analysis of RC beams using a hybrid shear-flexural fibre beam model. Engineering Computations, Vol. 31 (7), in press.

Ferreira, D., Crespo, M. D., Marí, A. and Bairán, J. (2014c). Thermo-mechanical simulation of the ConCrack Benchmark RL1 test with a filament beam model. Engineering Structures, 73: 143-159.

FIB (2010). Shear and punching shear in RC and FRC elements Lausanne.

Hadi, M. N. S. (2003). Retrofitting of shear failed reinforced concrete beams. Composite Structures, 62: 1-6.

Hoque, M., Rattanawangcharoen, N. and Shah, A. H. (2007). 3D nonlinear mixed finiteelement analysis of RC beams and plates with and without FRP reinforcement. Computers and Concrete, 4(2): 135-156.

Kesse, G. and Lees, J. M. (2007). Experimental behavior of reinforced concrete beams strengthened with prestressed CFRP shear straps. Journal of Composites for Construction, 11(4): 375-383.Khalifa, A. and Nanni, A. (2002). Rehabilitation of rectangular simply supported RC beams with shear deficiencies using CFRP composites. Construction and Building Materials, 16: 135-146.

Kim, S.-W. and Vecchio, F. J. (2008). Modeling of shear-critical reinforced concrete structures repaired with fiber-reinforced polymer composites. Journal of Structural Engineering, 134(8): 1288-1299.

Kupfer, H., Hilsdorf, H. K. and Rusch, H. (1969). Behavior of concrete under biaxial stresses. ACI Journal, 66(8): 656-666. 
Lee, H. K., Ha, S. K. and Afzal, M. (2008). Finite element analysis of shear-deficient RC beams strengthened with CFRP strips/sheets. Structural Engineering and Mechanics, 30(2): 247-261.

Mander, J. B., Priestley, M. J. N. and Park, R. (1988). Theoretical stress-strain model for confined concrete. Journal of Structural Engineering, 114(8): 1804-1826.

Marí, A., Oller, E. and Bairán, J. (2011). Predicting the response of FRP-strengthened reinforced-concrete flexural members with nonlinear evolutive analysis models. Journal of Composites for Construction, 15(5): 799-809.

Marí, A. R. B. (2000). Numerical simulation of the segmental construction of three dimensional concrete frames. Engineering Structures, 22: 585-596.

Mohr, S., J. Bairán, et al. (2010). A frame element model for the analysis of reinforced concrete structures under shear and bending, Engineering Structures, 32(12), 39363954.

Mosallam, A. S. and Banerjee, S. (2007). Shear enhancement of reinforced concrete beams strengthened with FRP composite laminates. Composites Part B: Engineering, 38: 781793.

Ruano, G., Isla, F., Pedraza R. I., Sfer D. and Luccioni B. (2014). Shear retrofitting of reinforced concrete beams with steel fiber reinforced concrete. Construction and Building Materials, 54: 646-658.Shamsai, M., Sezen, H. and Khaloo, A. (2007). Behavior of reinforced concrete beams post-tensioned in the critical shear region. Engineering Structures, 25: 1217-1229.

Souza, H. R. and Appleton, J. (1997). Behaviour of shear-strengthened reinforced concrete beams. Materials and Structures, 30: 81-90.

Souza, H. R. and Appleton, J. (1997). Flexural behaviour of strengthened reinforced concrete beams. Materials and Structures, 30: 154-159.

Taljsten, B. (2003). Strengthening concrete beams for shear with CFRP sheets. Construction and Building Materials, 17: 15-26.

Vecchio, F. J. and Collins, M. P. (1986). The modified compession-fiel theory for reinforced concrete elements subjected to shear. ACI Journal, 83(2): 1357-1417. 
Table 1 - Characteristics of the experimental tests from Altin et al. (2013) simulated with the proposed model

Table 2 - Properties of concrete

Table 3 - Properties of steel (from Altin et al. 2003)

Table 4 - Experimental and numerical results of the tests of Altin et al. (2003)

Figure 1 - Fundamentals of the formulation of the flexural and shear fibre beam models: a) structural level b) element level c) section level d) fibre level

Figure 2 - Backbone constitutive equations: a) concrete and b) steel

Figure 3 - Prestressed vertical reinforcement (clamps) in the shear-sensitive fibre beam model: a) bonded and b) unbonded

Figure 4 - Stress state in a fibre with stirrups and clamps

Figure 5 - Characteristics of the experimental tests of Altin et. al. (2003): a) longitudinal and b) sectional views (dimensions in $\mathrm{m}$, diameters of reinforcement in $\mathrm{mm}$ )

Figure 6-1D fibre beam model of the tests of Altin et al. (2003): a) longitudinal FE mesh and b) sectional fibre discretization

Figure 7 - Shear force vs. displacement for control beams of series $M /(V d)=4.5$ : a) total displacement and b) shear displacement

Figure 8 - Shear force vs. displacement for beams of series $\mathrm{M} /(\mathrm{Vd})=4.5$ : a) total displacement and b) shear displacement

Figure 9 - Shear force vs. displacement for beams of series $\mathrm{M} /(\mathrm{Vd})=3.3$ : a) total displacement and b) shear displacement

Figure 10 - Longitudinal stresses in the vertical reinforcement (stirrups and clamps) vs. shear force: a) series $\mathrm{M} /(\mathrm{Vd})=4.5$ and $\mathrm{b}) \mathrm{M} /(\mathrm{Vd})=3.3$

Figure 11 - Influence of the bonding condition of the clamps in the distribution of stresses in the vertical reinforcement: a) test S321 and b) test S331

Figure 12 - Gain of shear resistance with strengthening with vertical prestressed reinforcement

Figure 13 - Influence of the quantity of clamps in the shear capacity of beam S500A 


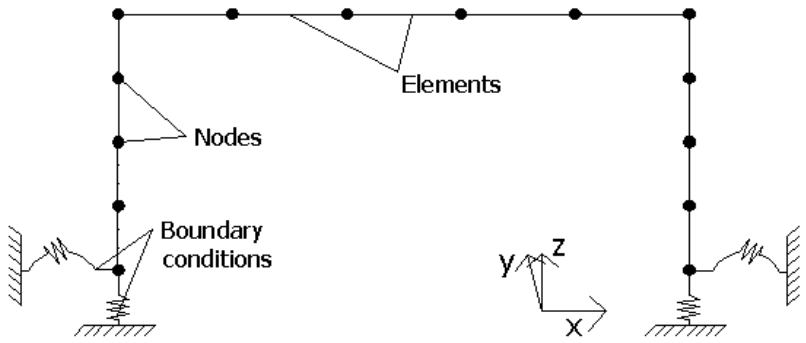

a)
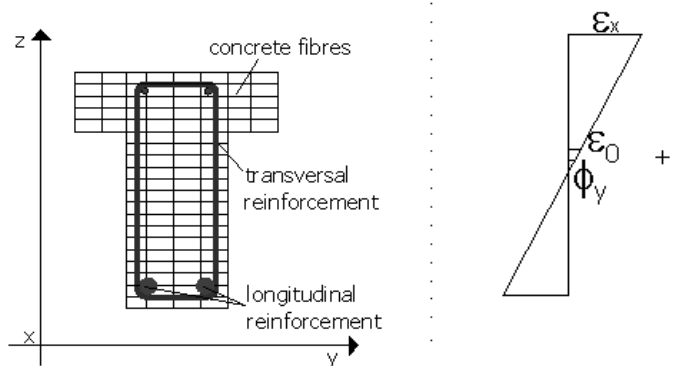

c)

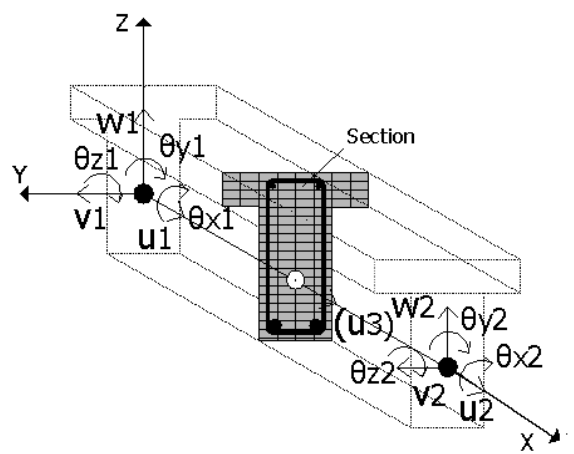

b)

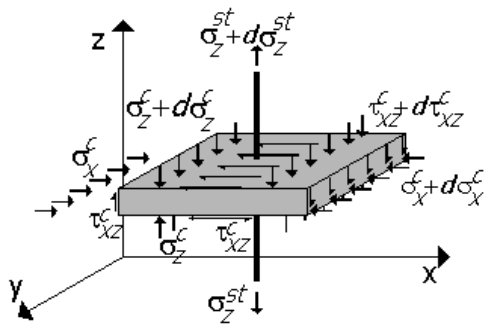

d)

Figure 1. Fundamentals of the formulation of the flexural and shear fibre beam models: a) structural level b) element level c) section level d) fibre level 


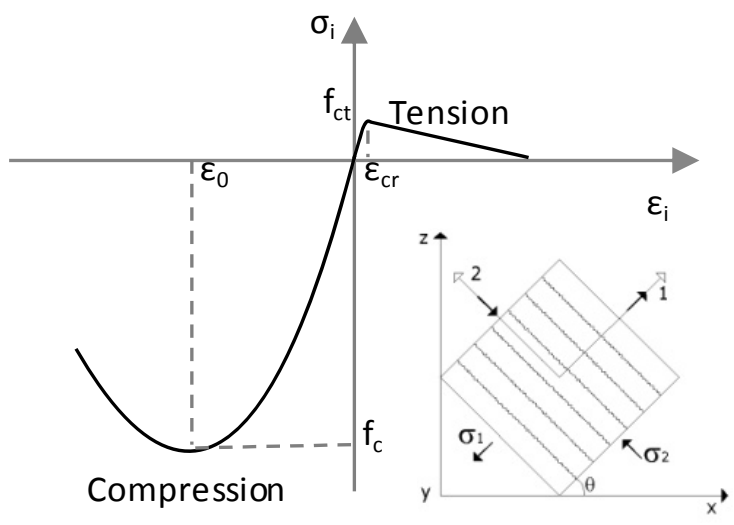

a)

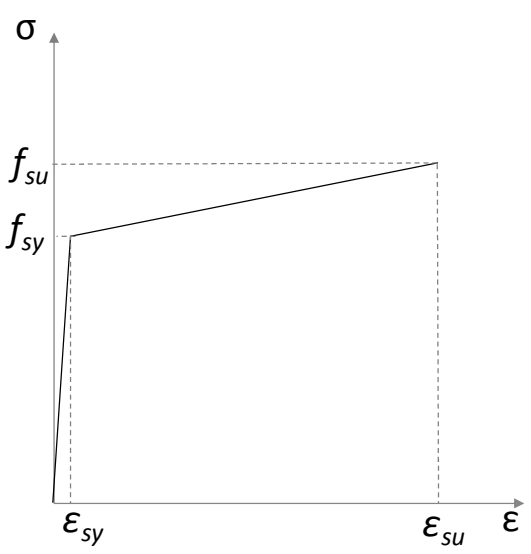

b)

Figure 2. Constitutive equations: a) concrete and b) steel 


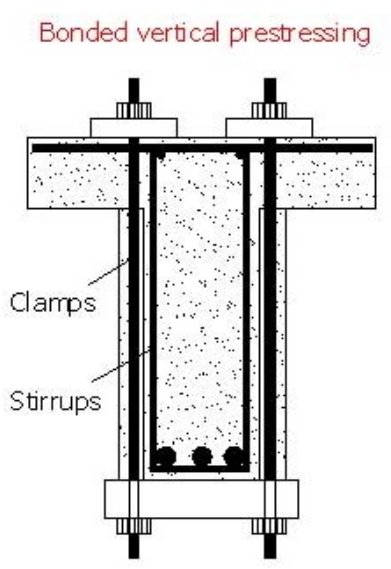

Mesh of the cross section

Strain state in the cross section
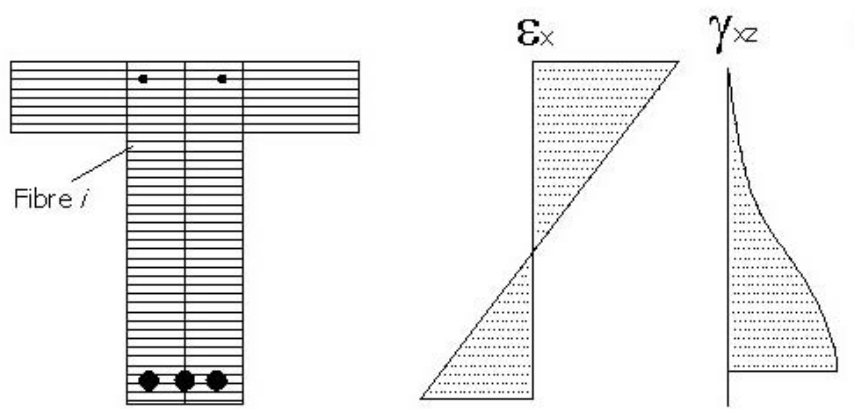

$\varepsilon_{z}$

Unbonded vertical prestressing

Mesh of the cross section
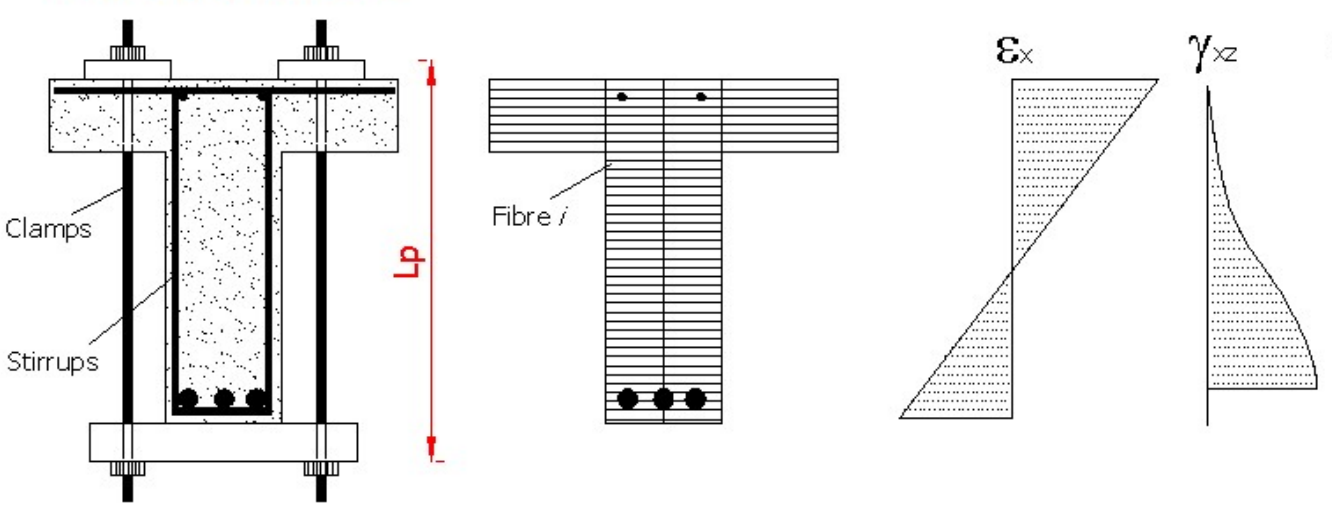

$\varepsilon_{z}$

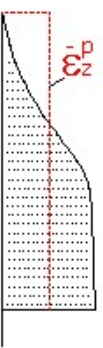

b)

Figure 3 -Prestressed vertical reinforcement (clamps) in the shear-sensitive fibre beam model: a) bonded and b) unbonded 


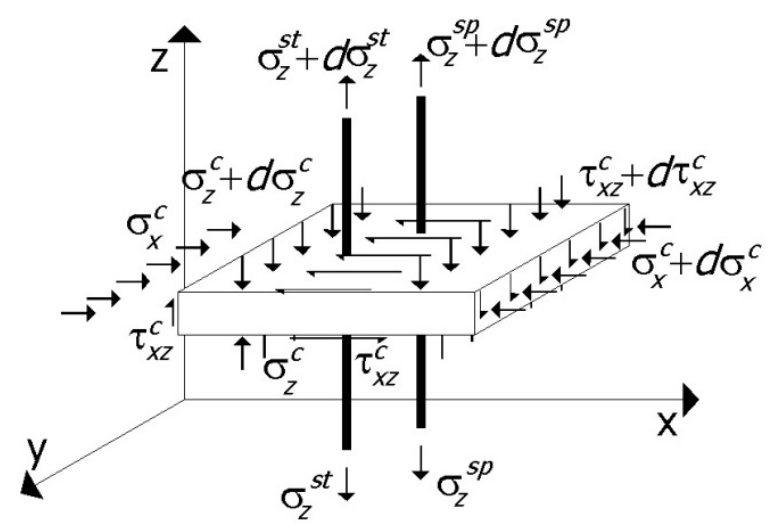

Figure 4 - Stress state in a fibre with stirrups and clamps 

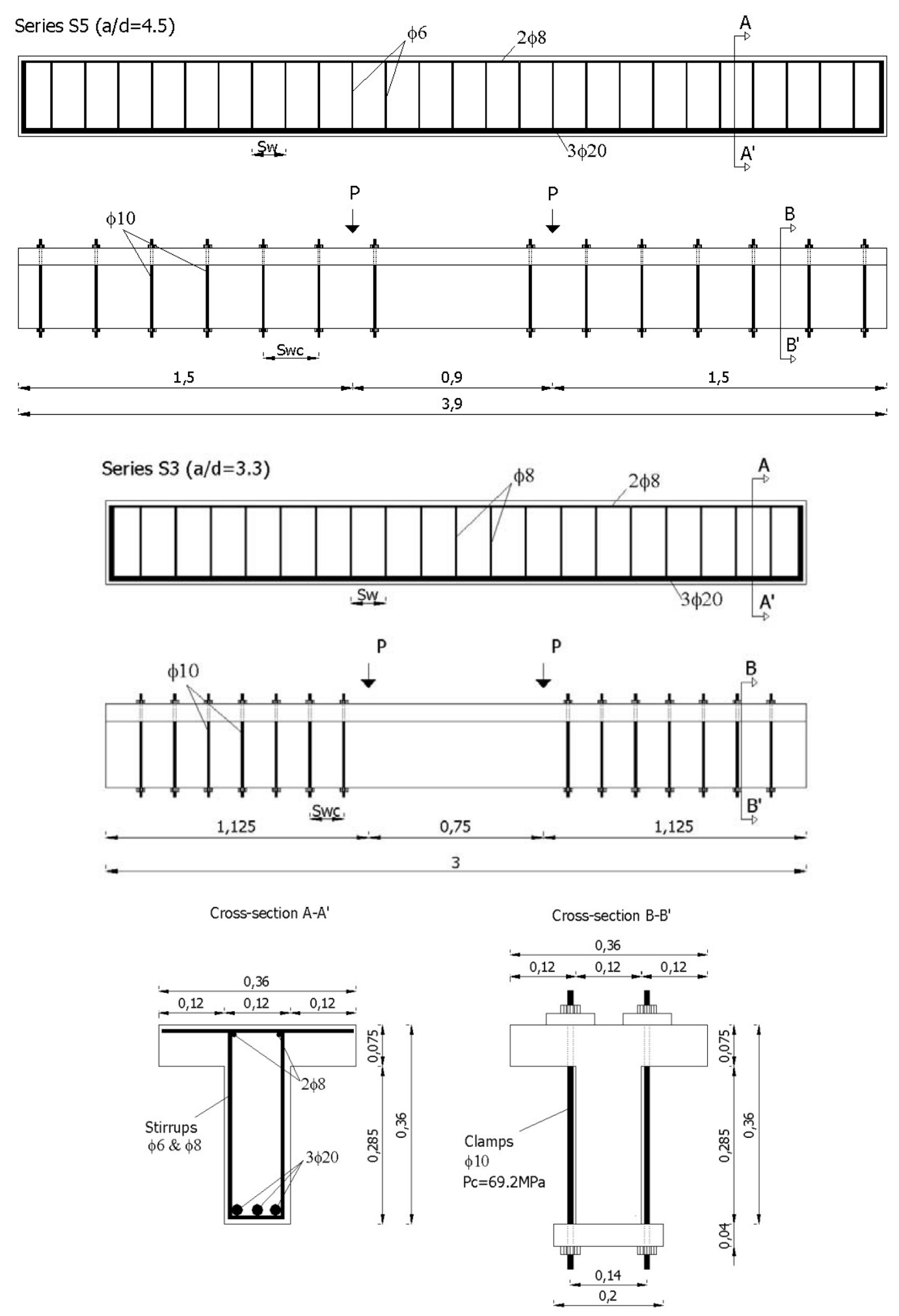

Figure 5. Characteristics of the experimental tests of Altin et. al. (2003) (dimensions in m, diameters of reinforcement in $\mathrm{mm}$ ) 


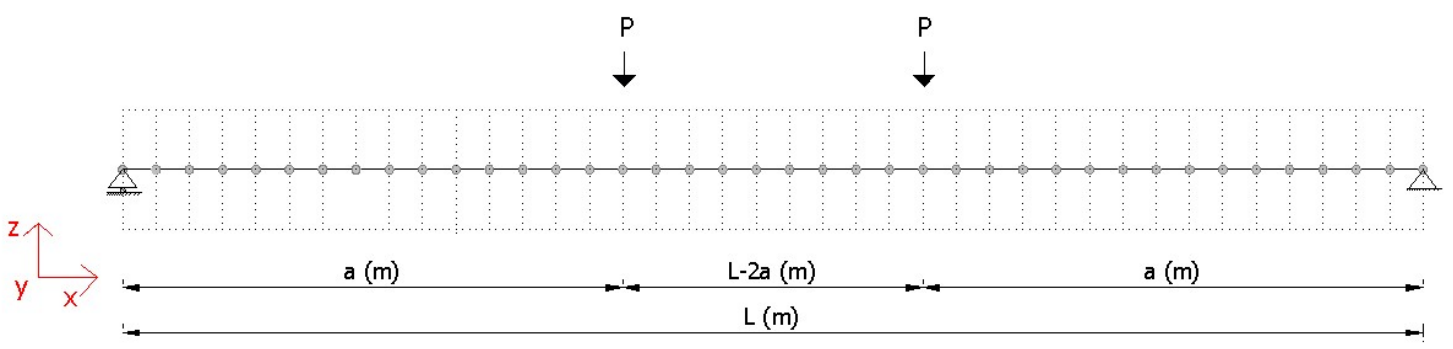

a)

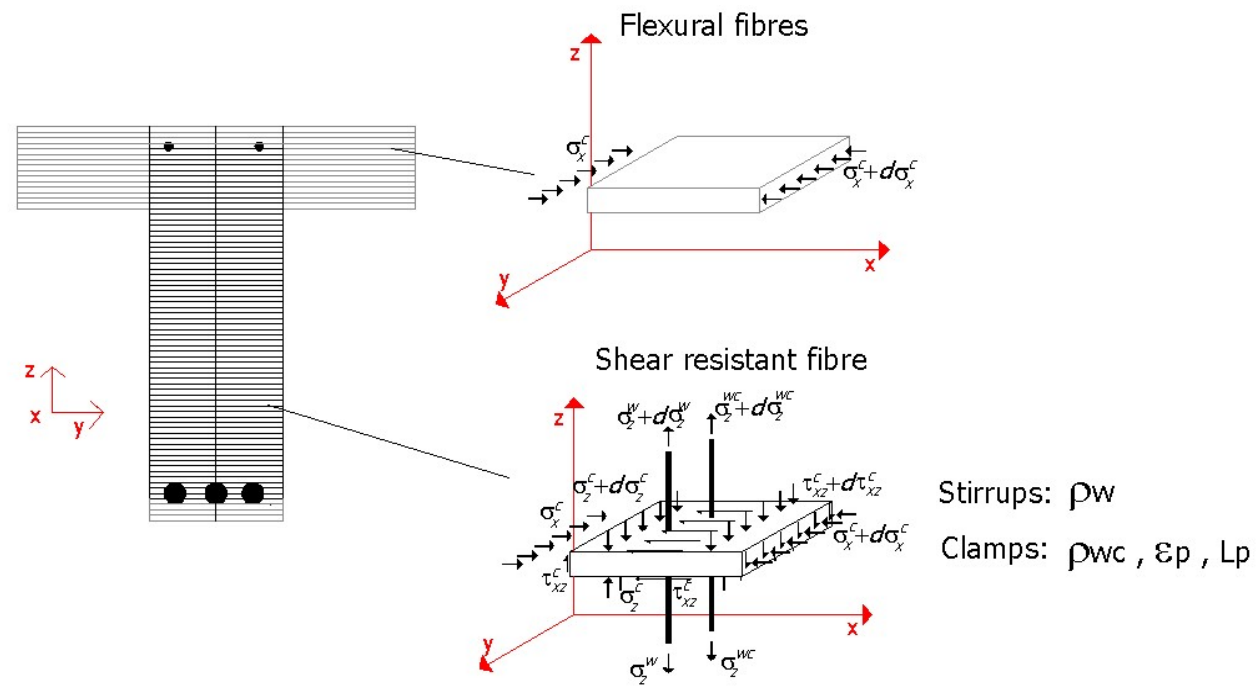

b)

Figure 6. 1D fibre beam model of the tests of Altin et al. (2003): a) longitudinal FE mesh and b) sectional fibre descritization 

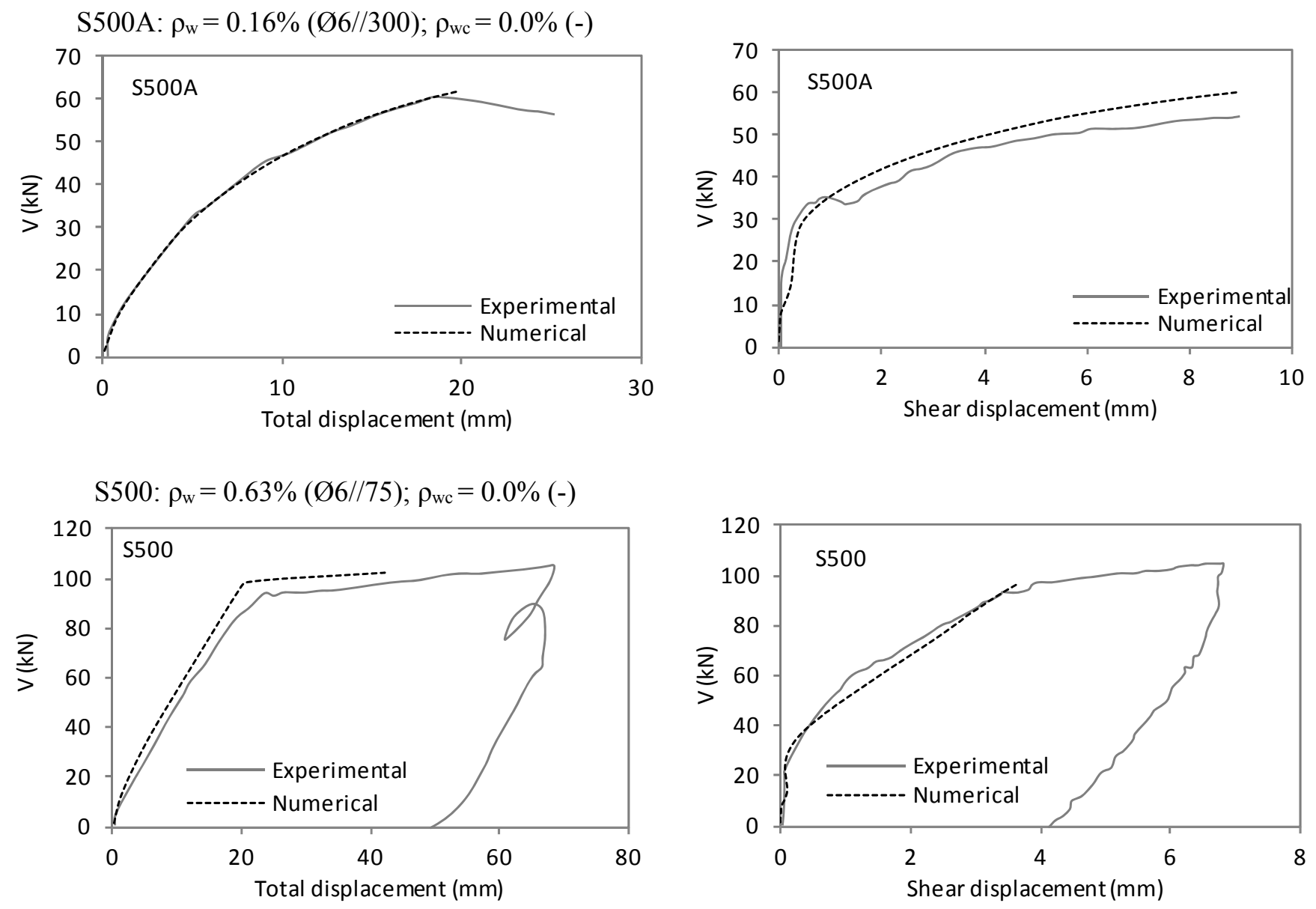

a)

b)

Figure 7. Shear force vs. displacement for control beams of series $M /(V d)=4.5$ : a) total displacement and b) shear displacement 
S500A: $\rho_{\mathrm{w}}=0.16 \%(\varnothing 6 / / 300) ; \rho_{\mathrm{wc}}=0.0 \%(-)$

S521: $\rho_{\mathrm{w}}=0.31 \%(\varnothing 6 / / 150) ; \rho_{\mathrm{wc}}=0.52 \%(\varnothing 10 / / 250)$
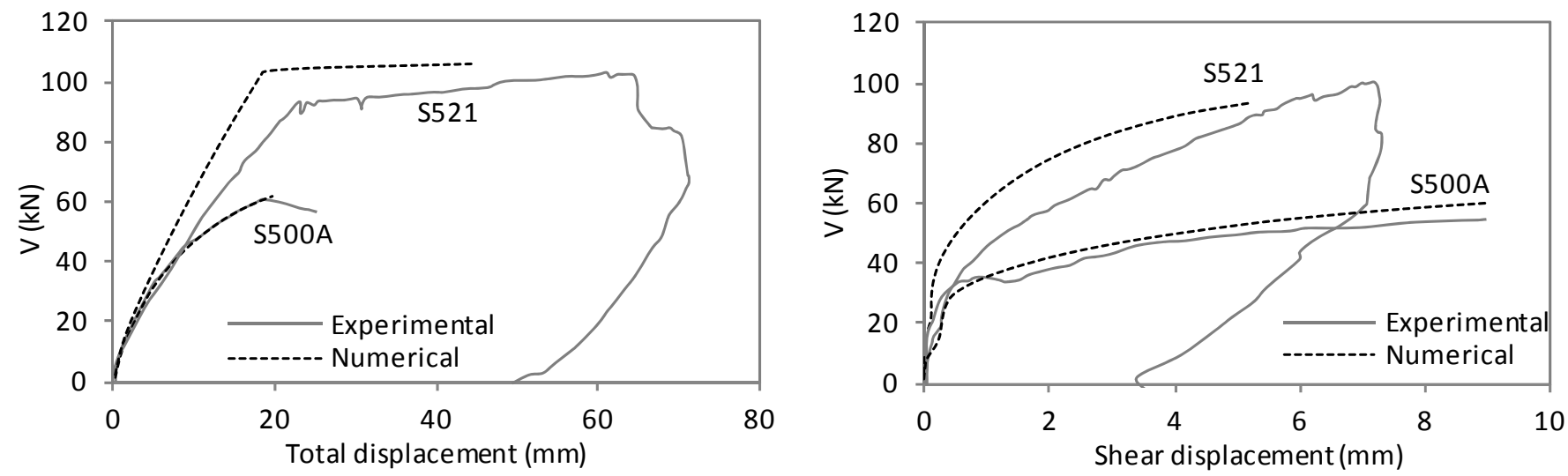

S500A: $\rho_{\mathrm{w}}=0.16 \%(\varnothing 6 / / 300) ; \rho_{\mathrm{wc}}=0.0 \%(-)$

S531: $\rho_{\mathrm{w}}=0.16 \%(\varnothing 6 / / 300) ; \rho_{\mathrm{wc}}=0.87 \%(\varnothing 10 / / 150)$

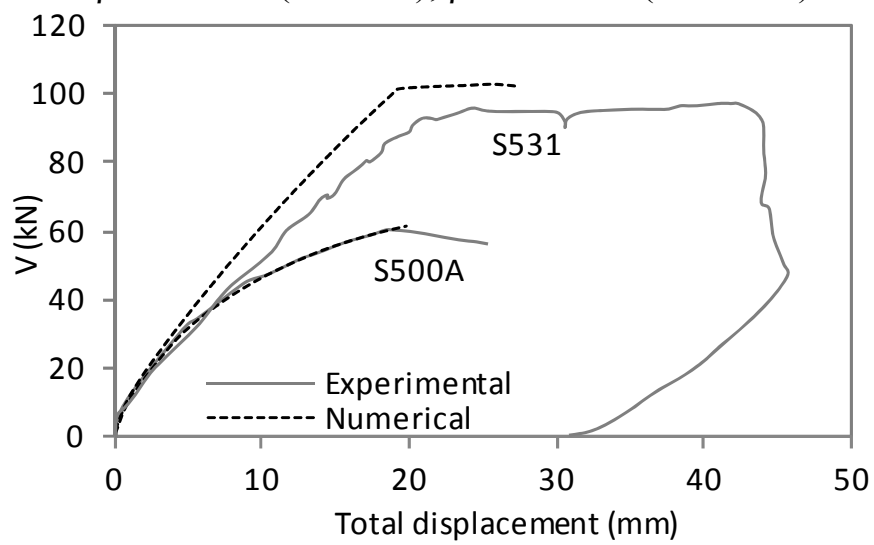

a)

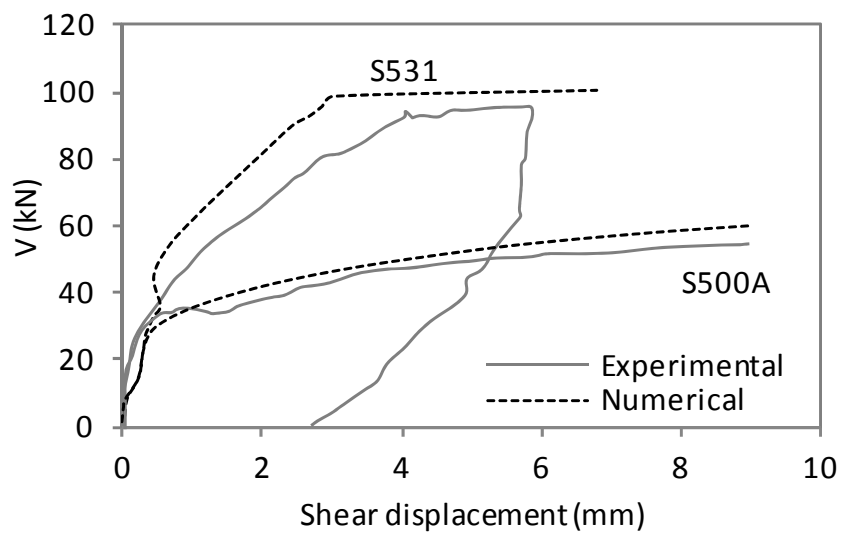

b)

Figure 8. Shear force vs. displacement for beams of series $\mathrm{M} /(\mathrm{Vd})=4.5$ : a) total displacement and $\mathrm{b})$ shear displacement 
S300: $\rho_{\mathrm{w}}=1.12 \%(\varnothing 8 / / 75) ; \rho_{\mathrm{wc}}=0.0 \%(-)$
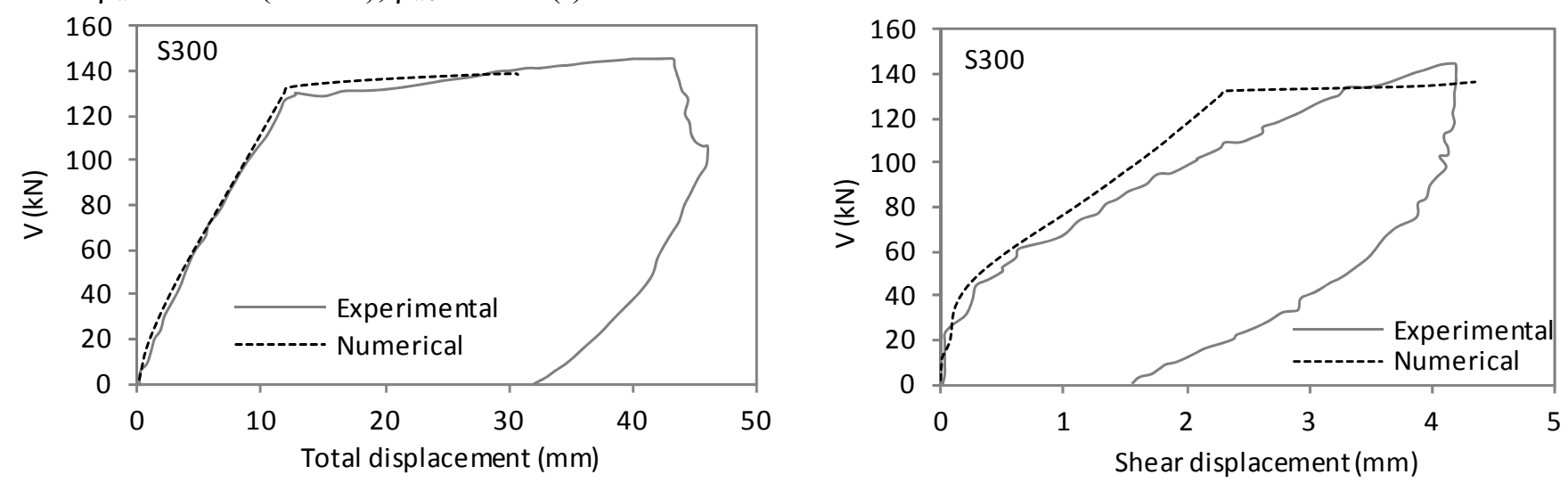

$\mathrm{S} 321: \rho_{\mathrm{w}}=0.56 \%(\varnothing 8 / / 150) ; \rho_{\mathrm{wc}}=0.90 \%(\varnothing 10 / / 145)$
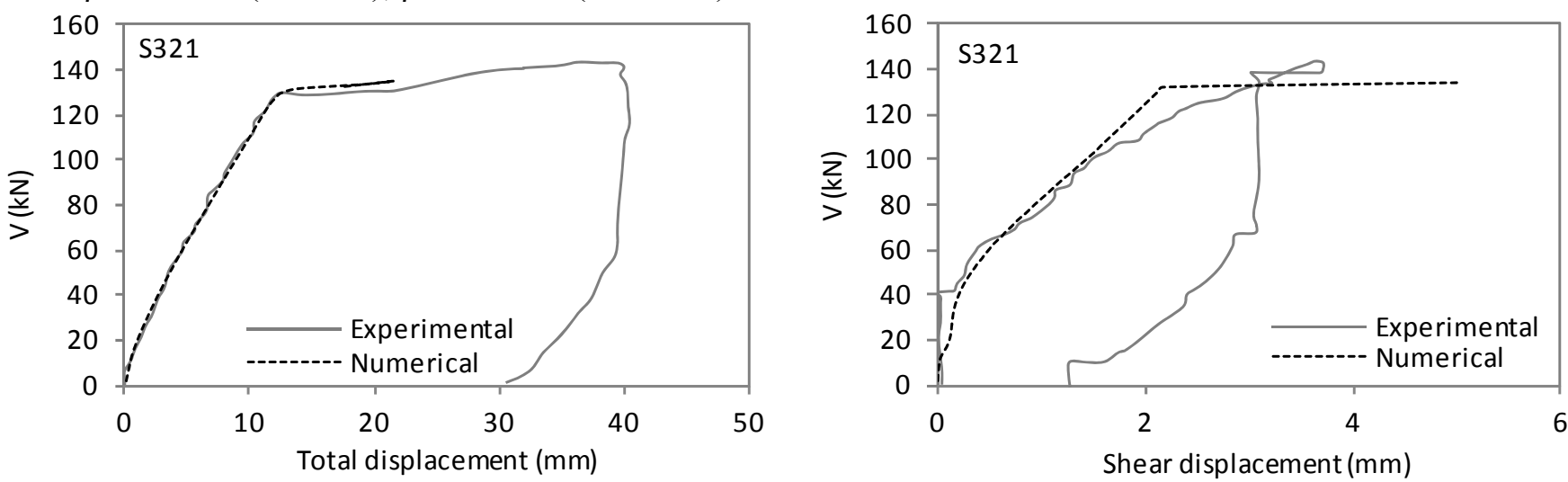

S331: $\rho_{\mathrm{w}}=0.28 \%(\varnothing 8 / / 300) ; \rho_{\mathrm{wc}}=1.31 \%(\varnothing 10 / / 100)$

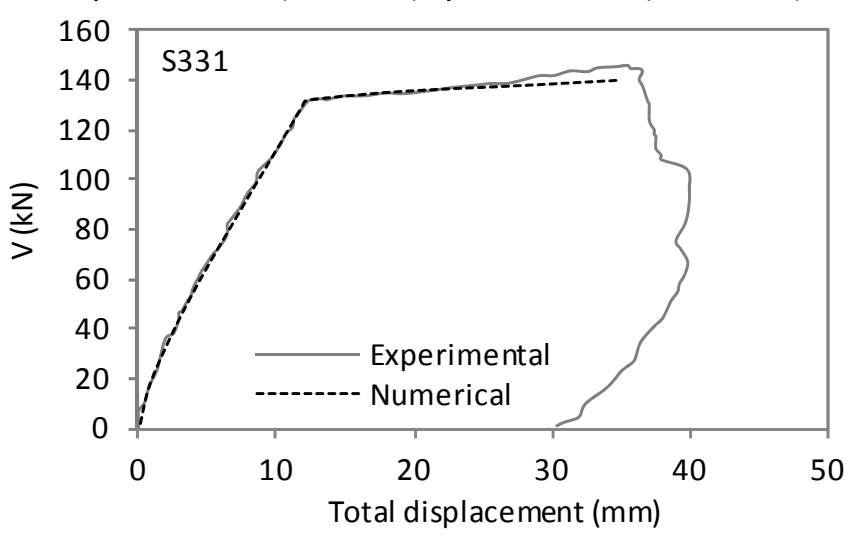

a)

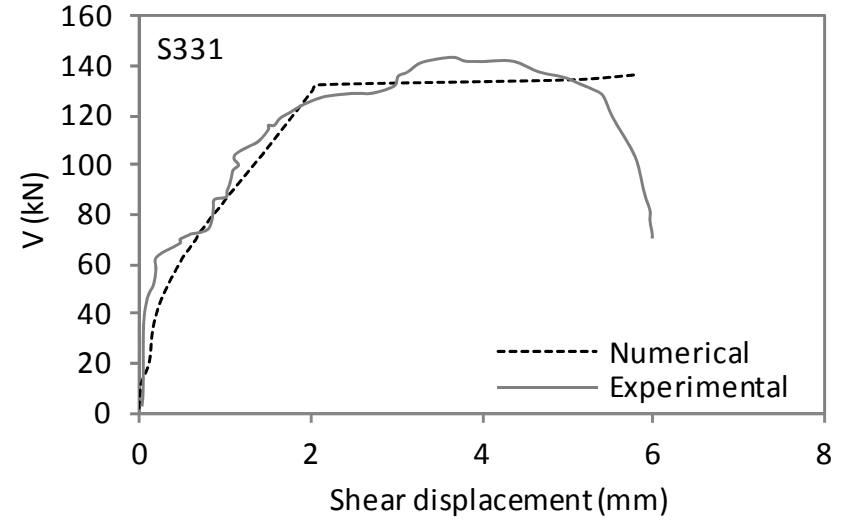

b)

Figure 9. Shear force vs. displacement for beams of series $M /(V d)=3.3$ : a) total displacement and b) shear displacement 


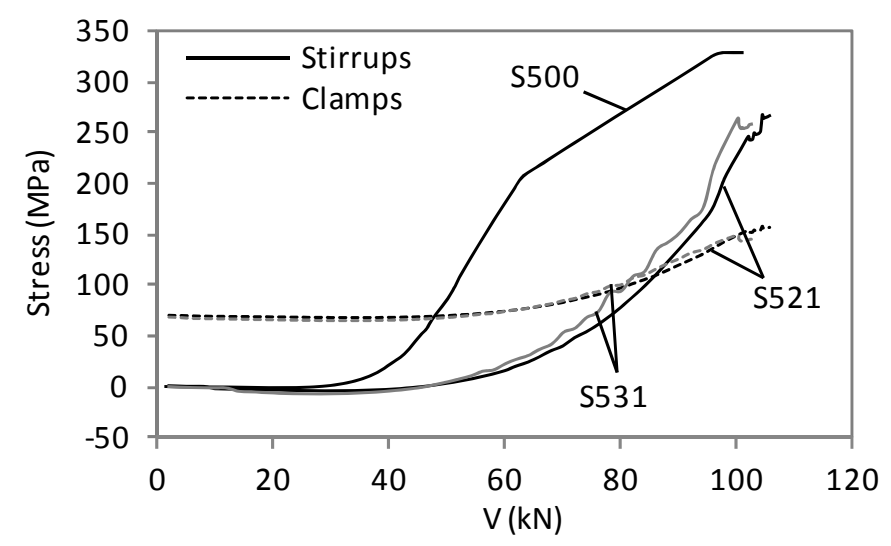

a)

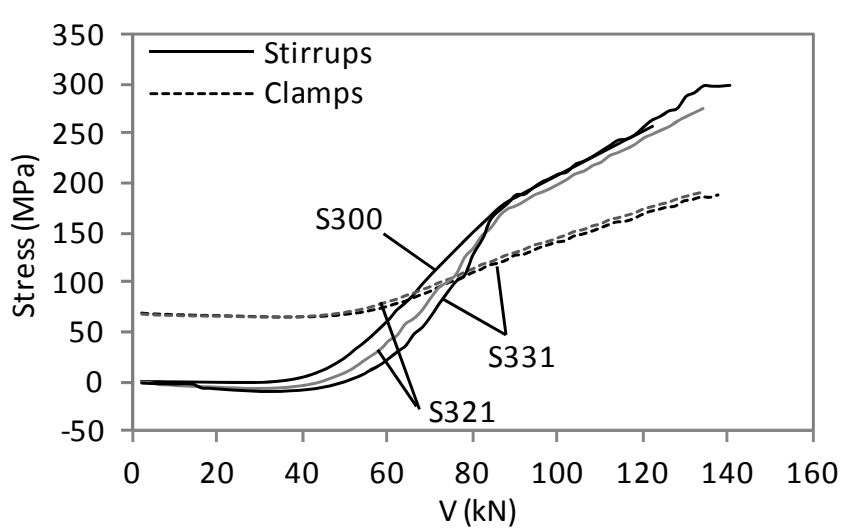

b)

Figure 10. Longitudinal stresses in the vertical reinforcement (stirrups and clamps) vs. shear force: a) series $\mathrm{M} /(\mathrm{Vd})=4.5$ and $\mathrm{b}) \mathrm{M} /(\mathrm{Vd})=3.3$ 


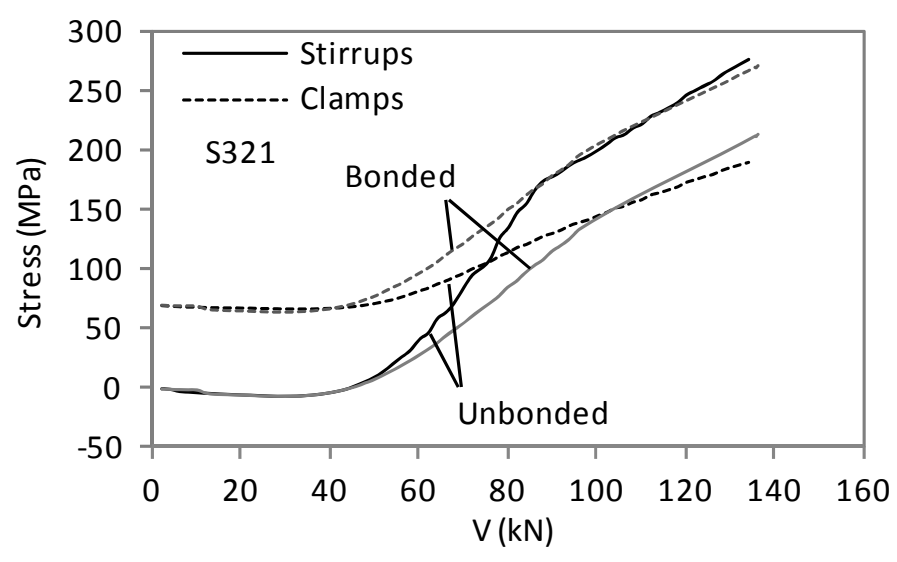

a)

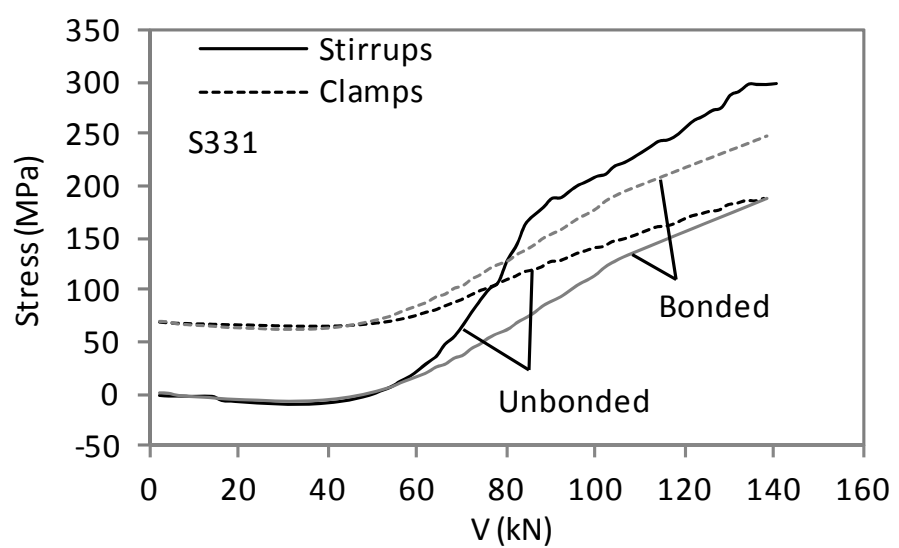

b)

Figure 11. Influence of the bonding condition of the clamps in the distribution of stresses in the vertical reinforcement: a) test $\mathrm{S} 321$ and b) test S331 


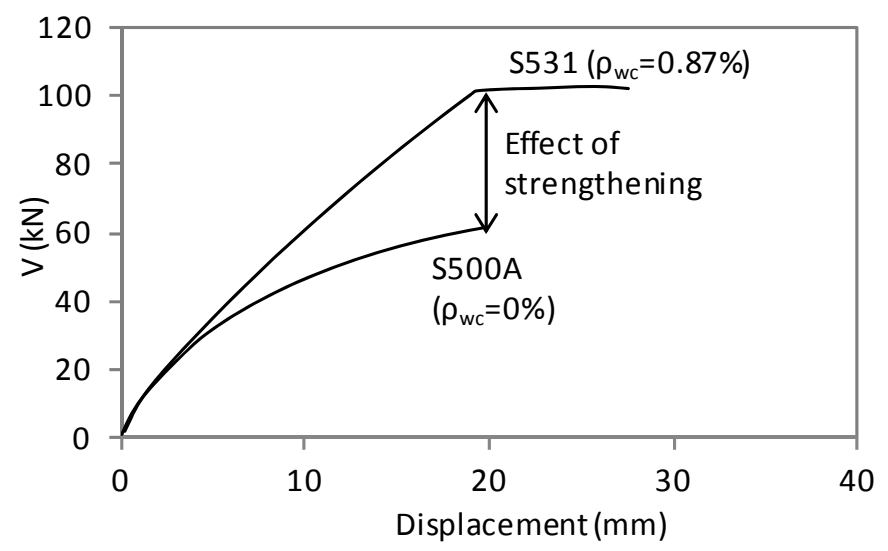

Figure 12. Gain of shear resistance with strengthening with vertical prestressed reinforcement 


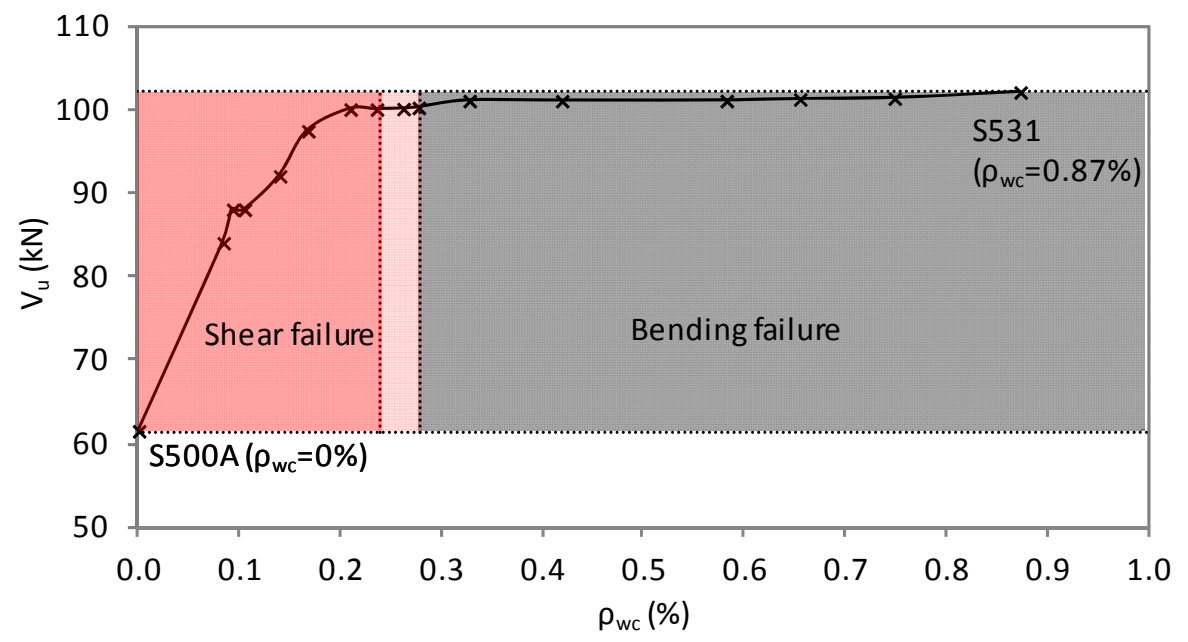

Figure 13. Influence of the quantity of clamps in the shear capacity of beam S500A 
Table 1 - Characteristics of the experimental tests from Altin et al. (2013) simulated with the proposed model

\begin{tabular}{|c|c|c|c|c|c|c|c|c|c|c|c|c|}
\hline Test & \multicolumn{4}{|c|}{ Geometry } & Concrete & \multicolumn{3}{c|}{ Stirrups } & \multicolumn{3}{c|}{ Clamps (at shear spans only) } \\
\hline & $\begin{array}{c}\mathrm{L} \\
(\mathrm{m})\end{array}$ & $\begin{array}{c}\mathrm{f}_{\mathrm{c}} \\
(\mathrm{MPa})\end{array}$ & $\begin{array}{c}\mathrm{d} \\
(\mathrm{m})\end{array}$ & $\mathrm{a} / \mathrm{d}$ & $\begin{array}{c}\mathrm{f}_{\mathrm{c}} \\
(\mathrm{MPa})\end{array}$ & $\varnothing / / \mathrm{s}_{\mathrm{w}}$ & $\begin{array}{c}\rho_{\mathrm{w}} \\
(\%)\end{array}$ & $\begin{array}{c}\rho_{\mathrm{w}} / \\
\rho_{\mathrm{w}, \mathrm{control}}\end{array}$ & $\varnothing / / \mathrm{s}_{\mathrm{wc}}$ & $\begin{array}{c}\rho_{\mathrm{cw}} \\
(\%)\end{array}$ & $\begin{array}{c}\rho_{\mathrm{cw}} / \\
\rho_{\mathrm{cw}, \text { control }}\end{array}$ & $\begin{array}{c}\mathrm{P}_{\mathrm{c}} \\
(\mathrm{MPa})\end{array}$ \\
\hline S500 & 3.9 & 24.0 & 0.335 & 4.5 & 24.0 & $\varnothing 6 / / 75$ & 0.63 & 1.00 & - & - & - & - \\
\hline S500-A & 3.9 & 21.0 & 0.335 & 4.5 & 21.0 & $\varnothing 6 / / 300$ & 0.16 & 0.25 & - & - & - & - \\
\hline S521 & 3.9 & 25.2 & 0.335 & 4.5 & 25.2 & $\varnothing 6 / / 150$ & 0.31 & 0.50 & $\varnothing 10 / / 250$ & 0.52 & 0.50 & 69.2 \\
\hline S531 & 3.9 & 20.1 & 0.335 & 4.5 & 20.1 & $\varnothing 6 / / 300$ & 0.16 & 0.25 & $\varnothing 10 / / 150$ & 0.87 & 0.75 & 69.2 \\
\hline S300 & 3.0 & 26.0 & 0.335 & 3.3 & 26.0 & $\varnothing 8 / / 75$ & 1.12 & 1.00 & - & - & - & - \\
\hline S321 & 3.0 & 23.9 & 0.335 & 3.3 & 23.9 & $\varnothing 8 / / 150$ & 0.56 & 0.50 & $\varnothing 10 / / 145$ & 0.90 & 0.50 & 69.2 \\
\hline S331 & 3.0 & 25.6 & 0.335 & 3.3 & 25.6 & $\varnothing 8 / / 300$ & 0.28 & 0.25 & $\varnothing 10 / / 100$ & 1.31 & 0.75 & 69.2 \\
\hline
\end{tabular}


Table 2 - Properties of concrete

\begin{tabular}{|c|c|c|c|c|c|}
\hline \multirow{2}{*}{ Test } & $\begin{array}{c}\text { Experimental value } \\
\text { (Altin et al. 2013) }\end{array}$ & \multicolumn{4}{|c|}{ Considered in the simulation } \\
\cline { 2 - 6 } & $\begin{array}{c}\mathrm{f}_{\mathrm{c}} \\
(\mathrm{MPa})\end{array}$ & $\begin{array}{c}\mathrm{f}_{\mathrm{c}}{ }^{*} \\
(\mathrm{MPa})\end{array}$ & $\varepsilon_{\mathrm{cu}}{ }^{*}$ & $\begin{array}{c}\mathrm{f}_{\mathrm{ct}}{ }^{+} \\
(\mathrm{MPa})\end{array}$ & $\begin{array}{c}\mathrm{E}_{\mathrm{c}}{ }^{+} \\
(\mathrm{GPa})\end{array}$ \\
\hline S500 & 24.0 & 25.2 & 0.0131 & 2.58 & 29.0 \\
\hline S500-A & 21.0 & 21.1 & 0.0067 & 2.29 & 27.5 \\
\hline S521 & 25.2 & 25.3 & 0.0127 & 2.59 & 29.1 \\
\hline S531 & 20.1 & 21.7 & 0.0209 & 2.33 & 27.8 \\
\hline S300 & 26.0 & 28.1 & 0.0191 & 2.77 & 30.0 \\
\hline S321 & 23.9 & 25.8 & 0.0187 & 2.62 & 29.2 \\
\hline S331 & 25.6 & 28.2 & 0.0235 & 2.78 & 30.0 \\
\hline
\end{tabular}

* Modified to account for confinement according to Mander's equation (Mander et al. 1988)

${ }^{+}$Determined from $f_{c}^{*}$ through equations of Eurocode 2 EN 1992-1 (CEN 2004) 
Table 3 - Properties of steel (from Altin et al. 2003)

\begin{tabular}{|c|c|c|c|c|}
\hline Type & $\begin{array}{c}\mathrm{f}_{\text {sy }} \\
(\mathrm{MPa})\end{array}$ & $\begin{array}{c}\mathrm{f}_{\mathrm{su}} \\
(\mathrm{MPa})\end{array}$ & $\begin{array}{c}\mathrm{E}_{\mathrm{s}} \\
(\mathrm{GPa})\end{array}$ & $\varepsilon_{\text {su }}$ \\
\hline$\varnothing 6$ & 328.5 & 409.1 & 210 & 0.237 \\
\hline$\varnothing 8$ & 299.8 & 448.5 & 210 & 0.271 \\
\hline$\varnothing 10$ & 276.9 & 391.7 & 200 & 0.325 \\
\hline$\varnothing 20$ & 517.3 & 843.1 & 210 & 0.169 \\
\hline
\end{tabular}


Table 4 - Experimental and numerical results of the tests of Altin et al. (2003)

\begin{tabular}{|c|c|c|c|c|c|c|c|c|c|c|c|c|c|c|c|c|}
\hline \multirow{3}{*}{ Test } & \multicolumn{3}{|c|}{ Shear cracking stage } & \multicolumn{6}{|c|}{ Yielding stage } & \multicolumn{7}{|c|}{ Failure stage } \\
\hline & \multirow{2}{*}{$\begin{array}{r}\text { Exp. } \\
V_{c s, e} \\
(\mathrm{kN}) \\
\end{array}$} & \multirow{2}{*}{$\begin{array}{r}\text { Num. } \\
\begin{array}{l}V_{c s, n} \\
(\mathrm{kN})\end{array} \\
\end{array}$} & \multirow{2}{*}{$\begin{array}{c}\text { Num/Exp } \\
V_{c s, n} / \\
V_{c s, e} \\
\end{array}$} & \multicolumn{2}{|c|}{ Exp. } & \multicolumn{2}{|c|}{ Num. } & \multicolumn{2}{|c|}{ Num/Exp } & \multicolumn{2}{|c|}{ Exp. } & \multicolumn{2}{|c|}{ Num. } & \multicolumn{2}{|c|}{ Num/Exp } & \multirow[b]{2}{*}{$\begin{array}{c}\text { Failure } \\
\text { mechanism }\end{array}$} \\
\hline & & & & $\begin{array}{r}V_{y, e} \\
(\mathrm{kN}) \\
\end{array}$ & $\begin{array}{c}d_{y, e} \\
(\mathrm{~mm})\end{array}$ & $\begin{array}{c}V_{y, n} \\
(\mathrm{kN}) \\
\end{array}$ & $\begin{array}{c}d_{y, n} \\
(\mathrm{~mm})\end{array}$ & $\begin{array}{l}V_{y, n} / \\
V_{y, e} \\
\end{array}$ & $\begin{array}{r}d_{y, n} / \\
d_{y, e} \\
\end{array}$ & $\begin{array}{r}V_{u, e} \\
(k N) \\
\end{array}$ & $\begin{array}{c}d_{u, e} \\
(\mathrm{~mm})\end{array}$ & $\begin{array}{r}V_{u, n} \\
(k N) \\
\end{array}$ & $\begin{array}{c}d_{u, n} \\
(\mathrm{~mm})\end{array}$ & $\begin{array}{l}V_{u, n} / \\
V_{u, e} \\
\end{array}$ & $\begin{array}{l}d_{u, n} / \\
d_{u, e} \\
\end{array}$ & \\
\hline S500 & 20.0 & 22.5 & 1.13 & 92.5 & 22.0 & 94.5 & 19.2 & 1.02 & 0.87 & 104.0 & 69.0 & 102.3 & 42.2 & 0.98 & 0.61 & Flexure $\checkmark$ \\
\hline S500A & 18.7 & 21.0 & 1.12 & \multicolumn{6}{|c|}{ Brittle shear failure } & 61.5 & 19.0 & 61.5 & 19.8 & 1.00 & 1.04 & Shear $\checkmark$ \\
\hline S521 & 23.4 & 21.0 & 0.90 & 97 & 25.0 & 97.5 & 18.9 & 1.00 & 0.75 & 102.5 & 69.0 & 105.7 & 42.9 & 1.03 & 0.62 & Flexure $\checkmark$ \\
\hline S531 & 26.4 & 21.0 & 0.80 & 92.5 & 25.2 & 93.0 & 17.9 & 1.01 & 0.71 & 93.2 & 29.0 & 102.0 & 26.1 & 1.09 & 0.90 & Flexure $\checkmark$ \\
\hline S300 & 21.8 & 26.0 & 1.19 & 133.5 & 14.4 & 130.0 & 12.0 & 0.97 & 0.83 & 147.5 & 44.2 & 138.0 & 28.5 & 0.94 & 0.64 & Flexure $\checkmark$ \\
\hline S321 & 24.0 & 20.0 & 0.83 & 132.0 & 13.1 & 130.0 & 11.8 & 0.98 & 0.90 & 143.7 & 38.2 & 135.4 & 17.5 & 0.94 & 0.46 & Flexure $\checkmark$ \\
\hline S331 & 22.2 & 24.0 & 1.08 & 133.0 & 13.5 & 130.0 & 11.8 & 0.98 & 0.88 & 146.5 & 36.5 & 140.3 & 32.5 & 0.96 & 0.89 & Flexure $\checkmark$ \\
\hline \multirow{2}{*}{\multicolumn{3}{|c|}{$\begin{array}{c}\text { Average } \\
\text { Standard deviation }\end{array}$}} & 1.01 & & & & & 0.99 & 0.82 & & & & & 0.99 & 0.74 & \\
\hline & & & 0.16 & & & & & 0.02 & 0.08 & & & & & 0.06 & 0.21 & \\
\hline
\end{tabular}

